Journal of Human and Environment of Tropical Bays ISSN 2675-1631

Published by Universidade do Estado do Rio de Janeiro

1: 9-44. 2020

doi: $10.12957 /$ jheotb.2020.45907

Artigo de Pesquisa

\title{
DINÂMICA DE PRAIA E SUSCEPTIBILIDADE ÀS ONDAS DE TEMPESTADES NO LITORAL DA ILHA GRANDE (ANGRA DOS REIS - RJ)
}

BEACH DYNAMICS AND SUSCEPTIBILITY TO STORM WAVES ON THE COAST OF ILHA GRANDE (ANGRA DOS REIS - RJ)

\section{André Luiz Carvalho da Silva ${ }^{*}$, Jaciele da Costa Abreu Gralato ${ }^{1}$, Thamyres Cristine Farias Brum ${ }^{1}$, Carolina Pereira Silvestre ${ }^{2}$, Érika Cardoso da Silva Baptista ${ }^{1}$, Ana Beatriz Pinheiro²}

1. Universidade do Estado do Rio de Janeiro, Faculdade de Formação de Professores - Dgeo. Rua Francisco Portela, 1470 - Patronato, São Gonçalo - RJ, CEP 24435-005.

2. Universidade Federal Fluminense - Programa de Pós-Graduação em Dinâmica dos Oceanos e da Terra. Av. Gal. Milton Tavares de Souza, s/no - Campus da Praia Vermelha, Boa Viagem, Niterói - RJ, CEP: 24210-346.

* Autor DE CORRESPONDÊnCIA: ANDRELCSILVAGEOUERJ@gMAIL.COM ORCID:0000-0002-2912-7860

\begin{tabular}{|c|c|}
\hline RECEBIDO EM 11DE OUTUBRO DE 2019 & \multirow{5}{*}{$\begin{array}{l}\text { CITAÇÃO: } \\
\text { Silva A.L.C.; Gralato J.C.A.; Brum T.C.F.; } \\
\text { Silvestre C.P.; Baptista É.C.S. \& Pinheiro } \\
\text { A.B. DINÂMICA DE PRAIA E SUSCEPTIBILIDADE ÀS } \\
\text { ONDAS DE TEMPESTADES NO LITORAL DA ILHA } \\
\text { GRANDE (ANGRA DOS REIS - RJ). J. of Human } \\
\text { and Environment of Tropical Bays } 1: 9- \\
44,2020 \text {. } \\
\text { doi: } 10.12957 / \text { jheotb. } 2020.45907\end{array}$} \\
\hline VERSÃO REVISADA EM 17 DE DEZEMBRO DE 2019 & \\
\hline ACEITO EM 21 DE DEZEMBRO DE 2019 & \\
\hline PUBLICADO EM 17 DE JANEIRO DE 2020 & \\
\hline EDITOR RESPONSÁVEL: L.F. SKINNER (UERJ) & \\
\hline
\end{tabular}

\section{RESUMO}

O presente estudo objetivou caracterizar a dinâmica e a susceptibilidade de algumas praias da Ilha Grande (Angra dos Reis, RJ) às ondas de tempestades. Foram selecionadas um total de seis praias: Provetá, Lopes Mendes e Dois Rios (voltadas para o Oceano Atlântico), Grande Araçatiba, Abraão e Pouso (voltadas para o continente). Os monitoramentos foram realizados sazonalmente e foram adquiridos 72 perfis topográficos e 164 amostras de sedimentos na porção emersa e submarina das praias para análise granulométrica e morfoscopia. As praias voltadas para o oceano, como Lopes Mendes e Provetá, apresentaram maior dinâmica e vulnerabilidade às ressacas. A praia de Lopes Mendes, em especial, exibiu forte corrente de deriva litorânea e de retorno, formando canais proeminentes na porção submarina. Tempestades de maior magnitude alcançam o limite interno das praias estudadas na porção sul da ilha e removem grande quantidade de sedimentos, causando exposição de raízes e derrubando árvores; em Provetá, essas ondas também são responsáveis pela destruição de casas no limite interno da praia. As praias voltadas para o 
continente são menos dinâmicas, mas também se apresentam vulneráveis às ressacas, produzindo ondulações suficientemente fortes para dificultar o embarque e desembarque de passageiros nessas áreas. A dinâmica sedimentar é caracterizada pela mobilidade de materiais entre as partes emersa e submersa das praias e, no caso de Lopes Mendes e Dois Rios, ao longo das mesmas pela corrente de deriva litorânea. A granulometria e o grau de selecionamento dos sedimentos variam bastante, com o predomínio de areia quartzosa, subangular, média, fina a muito fina nas praias voltadas para o oceano, com diminuição do selecionamento do pós-praia para a face de praia; e areia quartzosa, predominantemente subangular, média, grossa e muito grossa nas praias voltadas para o continente, com variação do grau de selecionamento dessas praias.

PALAVRAS-CHAVE: Dinâmica de praia, sedimentação, erosão costeira, Ilha Grande-RJ.

\section{ABSTRACT}

The objective of the present study was the characterization of the dynamics and the vulnerability to storm waves of some beaches of the Ilha Grande (Angra dos Reis, Rio de Janeiro State). The beaches selected for this study were Provetá, Vila de Dois Rios and Lopes Mendes on the island's shore facing the open water of the Atlantic Ocean, and Grande Araçatiba, Vila do Abraão and Pouso on the island's continent facing shore. Seasonal field work was carried out for two years, obtaining 72 topographic profiles and 164 samples, from the subaerial and submarine parts of the beaches. The samples underwent grain-size and morphological analyses. Provetá beach and Lopes Mendes beach are the most dynamic and vulnerable to storm waves. Lopes Mendes, in particular, showed strong longshore current and rip currents in the center of the beach arc, which form prominent channels on the beachface; major storm events remove large quantities of the barrier's sediments causing the exposure of tree roots and finally their fall. These waves are also responsible for the destruction of buildings on the inner boundary of Provetá beach. Beaches facing the continent are also vulnerable to storm waves, despite respectively presenting low and moderate dynamics and producing ripples strong enough to make it difficult for passengers to board and disembark in these areas. The sediment dynamics of the study area are characterized by the mobility of the sands between the exposed and submarine parts of the beach. Lopes Mendes and Dois Rios Beaches show, in addition, longshore transport of sands. The grain size and sorting showed considerable variation, with predominance of fine to very-fine subangular quartz-rich sand on ocean-facing beaches, with sorting degree decreasing from the backshore to the beachface; and medium to very-coarse subangular quartz-rich sands on the beaches facing the continent, with varying the degree of sorting of these beaches.

KEY WORDS: Beach dynamics, sedimentation, coastal erosion, Ilha Grande-RJ.

\section{INTRODUÇÃO}

Este estudo objetivou caracterizar a dinâmica e a vulnerabilidade de algumas praias da Ilha Grande, em Angra dos Reis (RJ) (Figura 1), em relação à incidência de ondas de tempestades. Almejou-se também identificar as áreas suscetíveis à erosão costeira e a eventuais danos causados por ressacas através 
do conhecimento da dinâmica morfológica e sedimentar das praias monitoradas. Neste sentido, foram selecionadas as praias de Provetá, Dois Rios e Lopes Mendes, localizadas na face sul da ilha e voltadas para o oceano Atlântico; e Grande Araçatiba, Abraão e Pouso, na borda norte, voltadas para o continente (Figura 1).

A Ilha Grande (Figura 1) se configura como a maior ilha do litoral sul do estado do Rio de Janeiro (terceira maior do Brasil), com uma área total de 193 $\mathrm{km}^{2}$; e está inserida num trecho do litoral brasileiro pertencente à Bacia de Santos, que ocupa uma área total de cerca de $350.000 \mathrm{Km}^{2}$ (MOHRIAK, 2003). Atualmente, essa área abriga a principal fronteira petrolífera do país por conta da extração de petróleo na camada pré-sal. Aliado a isso, a presença do Terminal Petrolífero da Baía da Ilha Grande (TEBIG), juntamente com as Usinas Nucleares Angra 1 e 2 (em funcionamento) e Angra 3 (em construção), colocam a região da Ilha Grande num cenário de elevado crescimento econômico e industrial. 0 litoral da Ilha Grande, apesar da riqueza e diversidade de ambientes e da importância destes para os diversos ecossistemas costeiros, é praticamente desconhecido do ponto de vista geomorfológico e de sua vulnerabilidade a eventos de tempestades, assim como em relação aos riscos decorrentes das ressacas às diversas atividades existentes no litoral (turismo, pesca artesanal, navegação, moradia, etc.). Tais aspectos reforçam a necessidade de realização de estudos dessa natureza, cada vez mais essenciais diante do rápido crescimento das atividades ligadas ao turismo e à indústria na região.

Os litorais são influenciados por diversos processos e variáveis e estão em constante transformação, buscando alcançar uma situação de equilíbrio dinâmico através do confronto entre as diversas forças que exercem influência sobre os ambientes costeiros (DAVIS, 1985; CARTER, 1988; DAVIS e FITZGERALD, 2004; BIRD, 2008). O conhecimento da dinâmica costeira é fundamental para a compreensão do grau de vulnerabilidade aos eventos de tempestades e susceptibilidade à erosão costeira (BIRD, 2008). No litoral do estado do Rio de Janeiro, inúmeros problemas vêm sendo apontados por diversos autores relacionados ao efeito das ressacas e à destruição de estruturas urbanas por ondas de tempestades (MUEHE, 1979; SILVA et al., 1999; SANTOS et al., 2004; SILVA et al., 2008; SILVA et al., 2009; LINS-DE-BARROS e MUEHE, 2010; SILVA 
et al., 2014b; MUEHE et al., 2015; BULHÕES et al., 2016; SILVA et al., 2016; ECCARD et al., 2017).

O conceito de praia refere-se a um depósito sedimentar formado por sedimentos inconsolidados ao longo de uma costa sujeita à ação das ondas (DAVIS e FITZGERALD, 2004; BIRD, 2008). O ambiente praial pode ser compartimentado em três subambientes: pós-praia, frente de praia e face de praia (FRIEDMAN e SANDERS, 1978). A região do pós-praia (zona de supramaré) é a porção seca e geralmente horizontal ou ligeiramente inclinada da praia; durante a ocorrência de eventos de tempestades, principalmente combinado à maré alta, água e sedimentos tendem a alcançar a parte superior da praia (DAVIS e FITZGERALD, 2004). No pós-praia é comum a ocorrência de bermas, formadas durante a fase de reconstrução da praia, logo após os eventos de tempestade (FRIEDMAN e SANDERS, 1978; BIRD, 2008). A frente de praia (zona de intermaré) corresponde à área sujeita às oscilações diárias da maré, com concomitante interação com a dinâmica de ondas; o retrabalhamento de sedimentos é intenso devido à ação das ondas, correntes e das oscilações da maré. A face de praia (zona de submaré) é a parte submersa, onde se encontra a "zona de surf" e a área de arrebentação das ondas (DAVIS e FITZGERALD, 2004).

Davis (1985) e Bird (2008) consideram que as ondas, correntes e marés são os principais processos responsáveis pelas modificações no ambiente praial, levando em conta também a importância dos ventos, rios e, a longo prazo, as oscilações no nível do mar. As variações morfológicas que ocorrem nos perfis de praia resultam das mudanças sazonais na energia das ondas, causando um alargamento principalmente no verão, devido ao predomínio de ondas de baixa energia, que depositam sedimentos na parte emersa da praia formando um perfil mais largo típico dessa estação. O aumento na frequência e energia das ondas de tempestade tende a promover um estreitamento da praia e a formação de escarpas bastante íngremes, mais comum no inverno. Essas ondas retiram sedimentos da parte emersa e os depositam na parte submersa da praia (KOMAR, 1976; FRIEDMAN e SANDERS, 1978; DAVIS, 1985; CARTER, 1988; DAVIS e FITZGERALD, 2004; BIRD, 2008). Essas variações decorrem do comportamento dinâmico das praias (equilíbrio dinâmico) e, não necessariamente indicam a ocorrência de um processo erosivo. O termo erosão 
de praias refere-se a um processo de remoção de sedimentos sem a sua posterior reposição, resultando em perda efetiva, devido: (1) à elevação do nível do mar; (2) à instabilidade tectônica, incluindo subsidência; (3) às alterações climáticas, relacionadas com o aumento da frequência e intensidade das tempestades; (4) às mudanças no aporte sedimentar; e (5) à influência do homem (DAVIS, 1985; BIRD, 2008). Praias com estoque reduzido de sedimentos são mais susceptíveis às variáveis acima mencionadas, que condicionam os processos erosivos. Em praias arenosas o mineral quartzo é quase sempre predominante na composição dos sedimentos, que podem ser provenientes: do intemperismo e erosão do continente, da plataforma continental interna e do transporte pelas correntes litorâneas (FRIEDMAN e SANDERS, 1978; DAVIS, 1985). A textura dos sedimentos siliciclásticos é produzida por processos deposicionais e erosivos, e demanda o conhecimento do tamanho, do brilho e da morfologia, que pode contribuir para o entendimento da origem dos materiais (TUCKER, 1981).

\section{MATERIAIS E MÉTODOS}

\section{Área de estudo}

A área de estudo compreende as praias localizadas em diferentes setores da Ilha Grande, no município de Angra dos Reis (entre 23004' e 2314'S e entre

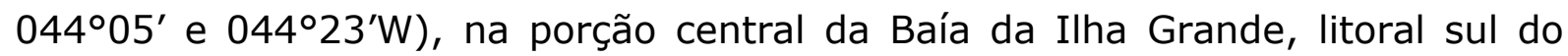
estado do Rio de Janeiro (Figura 1). As praias de Grande Araçatiba (Figura 2A), Abraão (Figura 2B) e Pouso (Figura 2C) (na face norte, voltadas para 0 continente), Provetá (Figura 2D), Dois Rios (Figura 2E) e Lopes Mendes (Figura 2F) (na face sul da ilha e voltadas para o Oceano Atlântico), estão entre as mais de 80 praias existentes na área de estudo e foram aqui escolhidas para o monitoramento das mudanças sazonais em resposta às alterações nas condições de mar (Figuras 1 e 2). A Ilha Grande constitui o topo de uma montanha submersa e apresenta altitudes inferiores a $500 \mathrm{~m}$ em relação ao nível do mar, com poucas exceções, como é o caso do Pico do Papagaio (com 959 m) e a Serra do Retiro (com $1031 \mathrm{~m}$ ) (MACIEL et al., 1984). A geomorfologia da Ilha Grande é caracterizada pelas vertentes e pela planície costeira flúvio-marinha, mais 
desenvolvida na borda sul da ilha, como em Lopes Mendes e nas praias do Sul e do Leste (Figura 1).
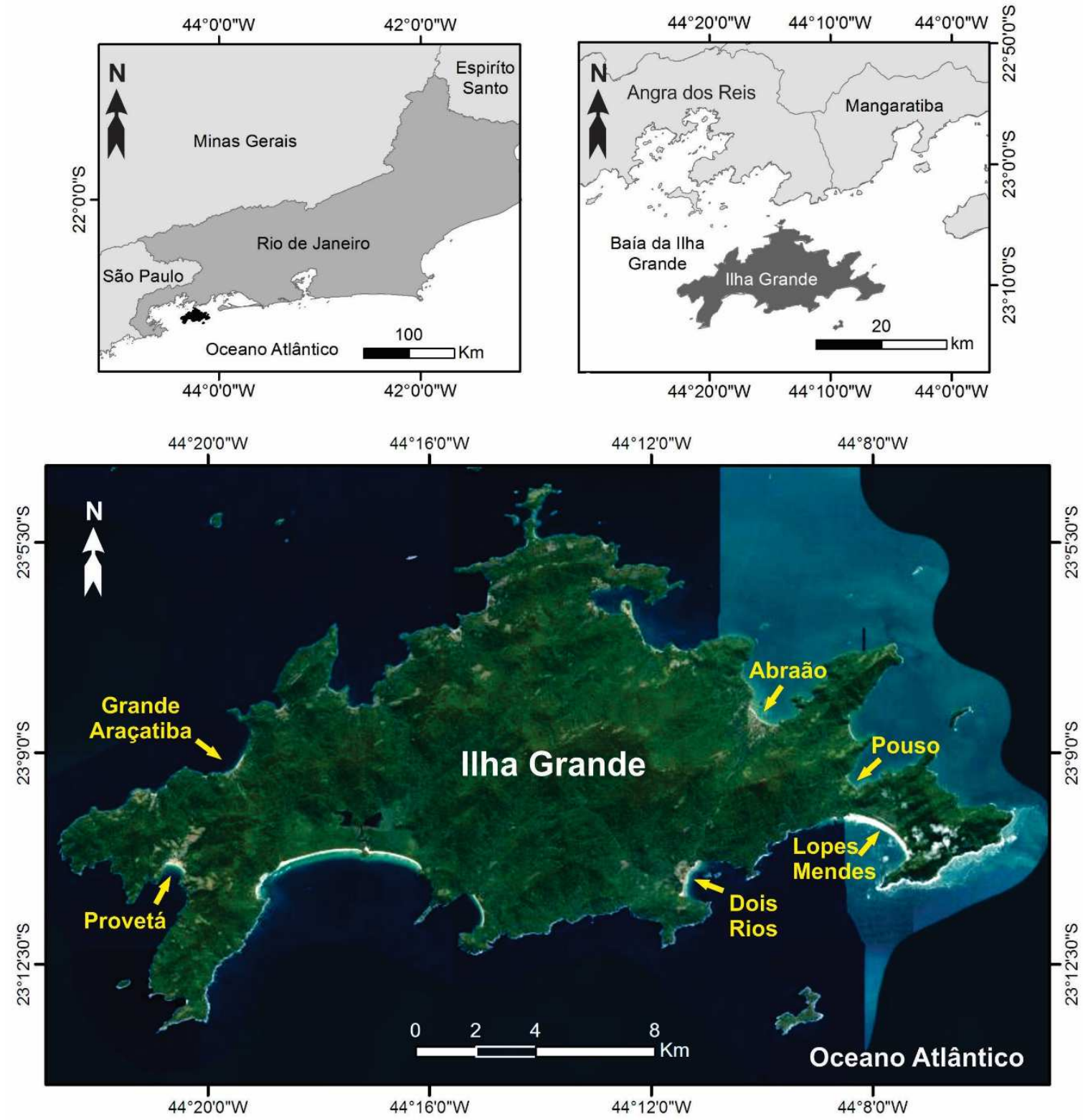

Figura 1: Localização da área de estudo e das praias selecionadas para o monitoramento.

O clima na região da Ilha Grande é tropical, com temperatura média entre $20^{\circ} \mathrm{C}$ e $26^{\circ} \mathrm{C}$, mais elevadas no verão, fortemente marcado por chuvas abundantes. A alta pluviosidade (em torno de $2000 \mathrm{~mm}$ por ano) está relacionada à aproximação das massas de ar úmidas vindas do oceano Atlântico, à intensa insolação e à influência do relevo, que atua como uma barreira orográfica (SALGADO et al., 2007). A abundante precipitação gera uma rede de 
cursos d'água de diferentes tamanhos, agrupados em 79 pequenas bacias hidrográficas (ROSA et al., 2009, INEA 2011 e 2013; entre outros). A ilha possui grandes áreas cobertas por vegetação remanescente de Mata Atlântica. Tratamse de áreas com elevada biodiversidade e que contam ainda com florestas preservadas devido, principalmente, à altitude e à dificuldade de acesso em decorrência do relevo acidentado (MESQUITA, 2004), com destaque para a porção centro-sul da ilha (OLIVEIRA, 2002). A Ilha é protegida por Unidades de Conservação (Parque Estadual da Ilha Grande, a Reserva Biológica da Praia do Sul e o Parque Estadual Marinho do Aventureiro) que buscam preservar o bioma Mata Atlântica e seus ecossistemas (OLIVEIRA, 2002; MMA, 2010; INEA, 2011 e 2013). A floresta ombrófila densa, que cobria quase toda a ilha, hoje é representada por formações secundárias, principalmente na parte norte e nas áreas próximas às vilas (OLIVEIRA, 2002). No ano de 2019, a Ilha Grande passou a ser considerada como Patrimônio Cultural e Natural Mundial pela Unesco, tornando-se, a partir de então, o primeiro sítio misto do Brasil.
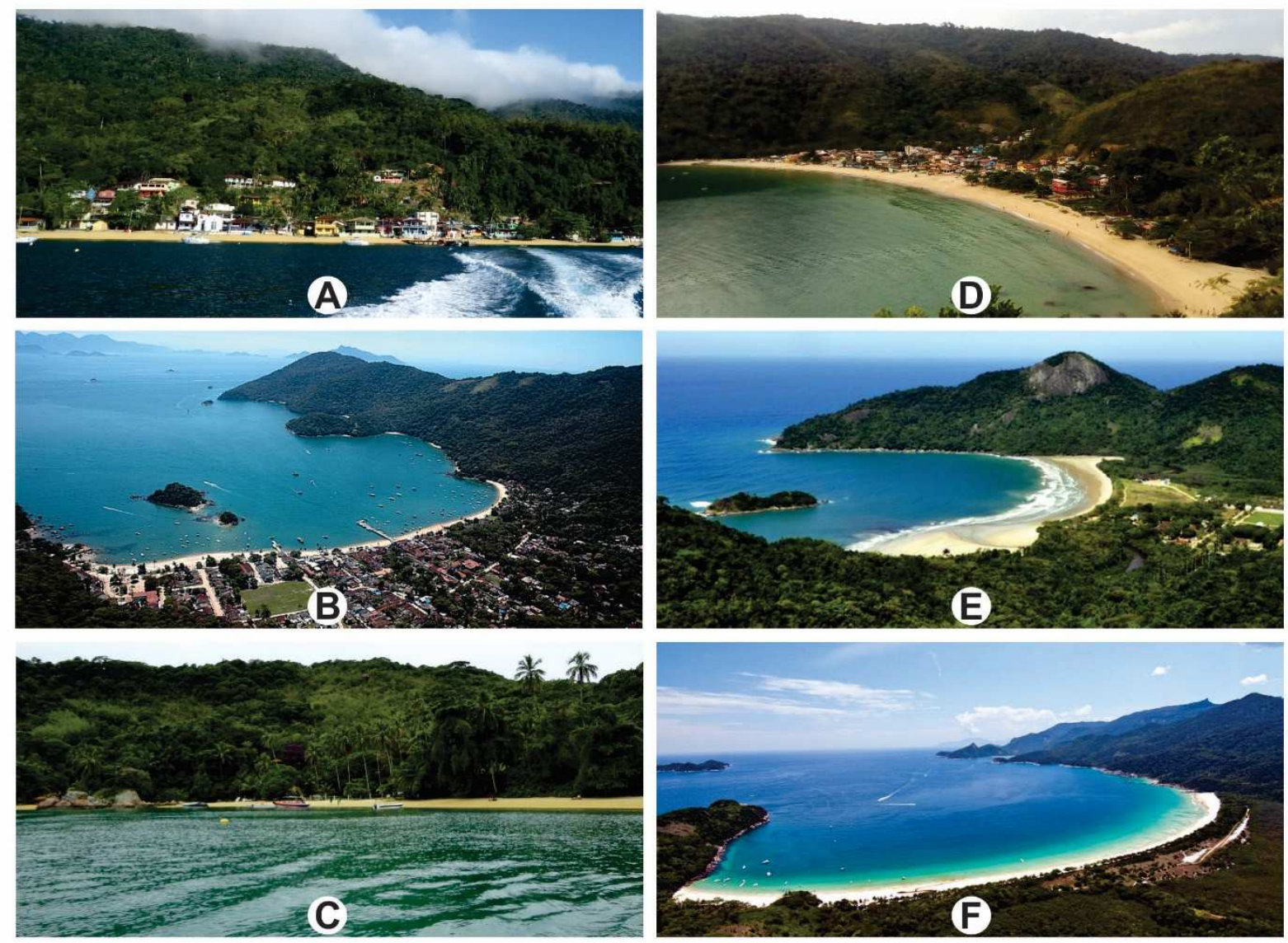
Figura 2: Praias estudadas ao redor da Ilha Grande: (A) Grande Araçatiba, (B) Abraão e (C) Pouso, na face norte; (D) Proveta, (E) Dois Rios e (F) Lopes Mendes, na face sul. Fotos: (A, B, C, D) André Silva, 2016; (E) Yamin, M., 2013; (F) Lara, L., 2014.

No litoral sul fluminense a maré é do tipo semidiurna e não ultrapassa 1,5 metro (DHN, 1980). As ondas representam o principal processo responsável pela dinâmica deste litoral, juntamente com as correntes costeiras. As praias localizadas na face sul da Ilha grande estão diretamente expostas à incidência direta de ondas; enquanto àquelas localizadas na borda norte da ilha e, principalmente, dentro de enseadas, estão parcialmente abrigadas da incidência direta das ondas. As ondas formadas sob condição de tempo bom são predominantes na maior parte do ano, oriundas do quadrante sul e, principalmente, de sudeste (GODOI et al., 2011; GRALATO, 2016). As ondas de tempestades, quase sempre provenientes de sudoeste, são causadas pela passagem ocasional de frentes frias (MUEHE, 1979; SILVA et al., 1999; SANTOS et al., 2004; SILVA et al., 2008; PARDAL, 2009; SILVA et al., 2009; SILVA et al., 2016). Segundo Godoi et al. (2011), essas ondas tendem a atingir regiões normalmente protegidas, podendo causar impactos nas estruturas costeiras. Esses danos podem ser ainda maiores quando ondas de tempestades ocorrem associadas à maré de sizígia que, somada a uma elevação momentânea do nível do mar, podem causar impactos ainda maiores sobre as estruturas localizadas próximas à linha d'água.

Conforme Belo et al. (2002), o relevo submarino da baía da Ilha Grande contribui para uma gradativa diminuição da energia das ondas e correntes ao longo da baía, com variações de leste (maior energia) para oeste (menor energia). Este padrão contribui para a diferenciação na sedimentação ao longo desta região, com sedimentos mais grossos predominando a leste, quando comparados com a região de menor energia a oeste, que conta com maior presença de sedimentos finos. A sedimentação na Baía da Ilha Grande é composta, basicamente, pelas frações areia muito fina na porção oeste e plataforma continental adjacente, areia média a grossa na porção leste, e silte no canal central e áreas abrigadas (MAHIQUES e FURTADO, 1989).

No litoral da Ilha Grande foram realizados 11 trabalhos de campo entre as estações do ano: por um período de 2 anos ( 7 monitoramentos), nas praias de 
Abraão, Pouso, Dois Rios e Lopes Mendes; e durante 1 ano (4 monitoramentos), nas praias de Provetá e Grande Araçatiba. Foram selecionados um total de 13 locais de monitoramento entre as seis praias ao redor da ilha (Figura 3). A maioria das praias estudadas se encontra em áreas afastadas e de difícil acesso, e fora necessário o uso de embarcações e sob condição de mar calmo, em se tratando das praias voltadas para mar aberto. Foram adquiridos um total de 72 perfis topográficos de praia, com concomitante coleta de 164 amostras de sedimentos, desde a porção emersa até a região submarina da praia.

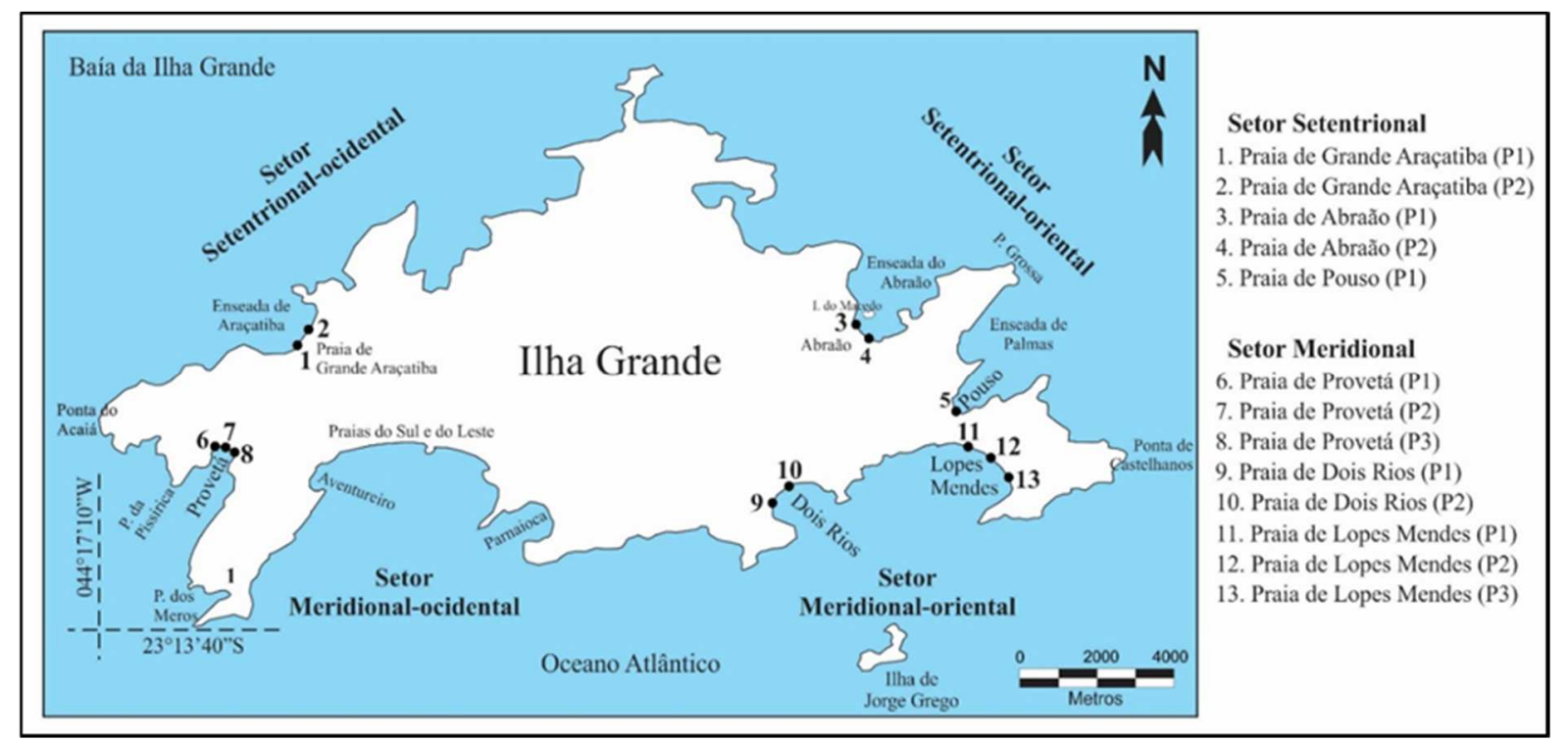

Figura 3: Locais de monitoramento nas praias estudadas na Ilha Grande.

O levantamento topográfico foi realizado desde o limite interno da praia, representado pelo início da vegetação de restinga, por uma escarpa de tempestade e/ou estruturas urbanas (muro, casas e poste); até a arrebentação das ondas, na porção submarina. Para tal, foi utilizado um nível topográfico, com o auxílio de uma mira e uma trena de 50 metros. Os perfis topográficos foram georreferenciados com GPS Garmin etrex 30 e sistema de navegação WGS 84. Os monitoramentos foram realizados sempre que possível na maré de quadratura, almejando uma menor interferência das oscilações diárias do nível do mar local. Os dados de topografia da praia foram processados no software Grapher 7, para o registro da morfologia praial. A sobreposição de perfis topográficos de praia permite identificar as áreas de maior ou menor dinâmica e os diferentes níveis de suscetibilidade de cada trecho aos eventos de 
tempestades (KOMAR, 1976). Por ocasião dos monitoramentos foram registradas algumas das características inerentes às condições de mar. O tipo de arrebentação e o período médio das ondas foram definidos com base em Laing (1998).

As areias das praias foram coletadas nos mesmos locais onde foram adquiridos os perfis topográficos (Figura 3) e em diferentes setores (pós-praia, frente de praia e face de praia). Em alguns monitoramentos o mar agitado impossibilitou a coleta de amostras na porção submarina da praia. A granulometria dos sedimentos foi feita com base no Sistema de Análise de Forma e Tamanho de Partícula com Processamento de Imagem Digital CAMSIZER; para tal, a amostra foi lavada para a remoção dos sais, seca na estufa $\left(50^{\circ} \mathrm{C}\right)$ e quarteada até cerca de 25 gramas. Os dados foram processados no programa Microsoft Excel e os resultados permitiram classificar os sedimentos de acordo com Wentworth (1922) apud Pettijohn (1975). A análise morfoscópica (arredondamento e brilho) foi realizada com base em Folk (1980), com concomitante observação da composição dos sedimentos. A morfoscopia foi realizada através da contagem e caracterização de 100 grãos de quartzo da fração predominante de cada amostra selecionada, utilizando-se uma lupa binocular com iluminação por reflexão.

\section{RESULTADOS}

As praias da Ilha Grande estão, na maioria dos casos, confinadas entre rochas do embasamento cristalino e podem variar de poucas centenas de metros (pocket beaches) até alguns quilômetros de extensão, como é o caso das praias de Lopes Mendes, Dois Rios e as praias do Sul e do Leste, na borda sul (Figura 3). Apresentam diferentes níveis de exposição à aproximação de ondas e aos eventos de tempestades, o que depende da localização e orientação das mesmas na ilha.

\section{Setor setentrional (voltado para o continente)}

O litoral norte ou setentrional da Ilha Grande (Figuras 1 e 3) possui aproximadamente 76 quilômetros de extensão, entre a Ponta do Acaiá (extremo oeste) e a Ponta de Castelhanos (extremo leste). Este setor compreende um total de 58 praias voltadas para o continente (BAPTISTA, 2017), dentre elas as 
três selecionadas para o monitoramento da dinâmica praial: Grande Araçatiba, Abraão e Pouso (Figuras 1, 2 e 3). Essas praias se encontram, em grande parte, abrigadas da incidência direta de ondas de tempestade, devido à localização destas em enseadas e entre promontórios rochosos (Figura 3).

\section{Praia de Grande Araçatiba}

A praia de Grande Araçatiba (Figura 2A), com 630 metros de extensão, localiza-se na Enseada de Araçatiba, voltada para o canal entre a Baía da Ilha Grande e o continente (Figuras 1 e 3; Tabela 1). Na Enseada de Araçatiba (Figura 3) predominam ondulações formadas pela ação dos ventos locais; e pela aproximação de ondas a partir do flanco oeste da Ilha Grande, mais proeminentes sob condição de tempestade. Na praia, essas pequenas ondas incidem principalmente do quadrante noroeste e arrebentam próximo à linha d'água devido ao gradiente acentuado da porção submersa. As medições das condições de mar durante os monitoramentos, indicam um período médio de 10,37 segundos e uma altura média de 0,4 metros na arrebentação, que variou entre os tipos plunging e spilling (Tabela 1). Correntes de retorno foram observadas em todos os monitoramentos, associadas à ocorrência de cúspides de praia.

Os perfis topográficos de praia no setor sudoeste (perfil 1) em Grande Araçatiba exibem variações discretas na morfologia e largura da praia (Figura 4A). A largura média da faixa de areia é de 30,6 metros, entre o mínimo de 26,5 m (inverno de 2016) e a máxima de 37 m (no verão de 2016), variando apenas $10,5 \mathrm{~m}$ entre os monitoramentos. O perfil praial exibiu uma morfologia em rampa, com cerca de $19^{\circ}$ de inclinação, com um ligeiro aumento da mesma na porção submarina, o que faz com que as ondas arrebentem próximo a linha d'água. No setor nordeste do arco praial, os perfis topográficos de praia (perfil 2) também mostram pouca variabilidade na largura e morfologia entre as estações (Figura 4A); a largura média da praia foi de 40,5 m; mais estreita no outono de 2016 (medindo $38 \mathrm{~m}$ ) e mais larga na primavera de 2016 (43,5 m), com apenas $5,5 \mathrm{~m}$ de diferença entre os monitoramentos (Figura 4A). O pós-praia é praticamente horizontal em função das bermas, facilmente observadas neste setor do arco praial, como registro dos momentos de incorporação de sedimentos durante a reconstrução do perfil praial (Figura 4A); a declividade da frente de 
Beach dynamics and susceptibility to storm waves

praia (em torno de $20^{\circ}$ ) se mantém semelhante à apresentada pela porção submarina (Figura 4A). 


\begin{tabular}{|c|c|c|c|c|c|c|c|c|c|c|c|c|}
\hline \multirow{2}{*}{ No } & \multirow{2}{*}{ Praia } & \multicolumn{2}{|c|}{ Localização } & \multirow{2}{*}{ Setor } & \multicolumn{4}{|c|}{ Condições de mar } & \multirow{2}{*}{\begin{tabular}{c|c} 
Frações \\
predominantes
\end{tabular}} & \multirow{2}{*}{$\begin{array}{c}\text { Classificação } \\
\text { Wentworth } \\
(1922)\end{array}$} & \multirow{2}{*}{ Comp.* } & \multirow{2}{*}{ Morfoscopia } \\
\hline & & Latitude & Longitude & & $H(m)$ & $T(s)$ & $\begin{array}{c}\text { Direçã } \\
\text { o }\end{array}$ & $\underset{+}{\text { Arrebentação }}$ & & & & \\
\hline 1 & $\begin{array}{c}\text { Grande } \\
\text { Araçatiba P1 }\end{array}$ & $\begin{array}{c}23^{\circ} 09^{\prime} 13.3^{\prime \prime} \\
\mathrm{S}\end{array}$ & $\begin{array}{c}044^{\circ} 19^{\prime} 29.0^{\prime \prime} \\
\text { W }\end{array}$ & $\begin{array}{c}\text { Setentrional } \\
\text { Ocidental }\end{array}$ & $0,2-0,3$ & $\begin{array}{l}6,9- \\
15,6\end{array}$ & $\mathrm{~s}$ & Plunging & $\begin{array}{l}\text { Areia Média a } \\
\text { Muito Grossa }\end{array}$ & Areia & Q/F/MP & $\begin{array}{l}\text { Muito Angular } \\
\text { Angular }\end{array}$ \\
\hline 2 & $\begin{array}{c}\text { Grande } \\
\text { Araçatiba P2 }\end{array}$ & $\begin{array}{c}23^{\circ} 09^{\prime} 05.3^{\prime \prime} \\
\mathrm{S}\end{array}$ & $\begin{array}{c}044^{\circ} 19^{\prime} 23.4^{\prime \prime} \\
W\end{array}$ & $\begin{array}{c}\text { Setentrional } \\
\text { Ocidental }\end{array}$ & $0,2-0,3$ & $\begin{array}{l}8,11- \\
12,28\end{array}$ & $\mathrm{~s}$ & Plunging & $\begin{array}{l}\text { Areia Grossa a } \\
\text { Média }\end{array}$ & Areia & $\mathrm{Q} / \mathrm{F}$ & Muito Angular \\
\hline 3 & Abraão P1 & $\begin{array}{c}23^{\circ} 08^{\prime} 18.4^{\prime \prime} \\
\mathrm{S}\end{array}$ & $\begin{array}{c}044^{\circ} 10^{\prime} 10.4^{\prime \prime} \\
W\end{array}$ & $\begin{array}{c}\text { Setentrional } \\
\text { Oriental }\end{array}$ & 0,17 & 9.68 & $\mathrm{NE}$ & Plunging & $\begin{array}{c}\text { Areia Média a } \\
\text { Grossa }\end{array}$ & Areia & $\mathrm{Q} / \mathrm{F} / \mathrm{MP}$ & Subangular \\
\hline 4 & Abraão P2 & $\begin{array}{c}23^{\circ} 08^{\prime} 29.1^{\prime \prime} \\
\mathrm{S}\end{array}$ & $\begin{array}{c}044^{\circ} 09^{\prime} 58.2^{\prime \prime} \\
W\end{array}$ & $\begin{array}{c}\text { Setentrional } \\
\text { Oriental }\end{array}$ & $0.2-0.15$ & 9.29 & $\mathrm{NE}$ & Plunging & $\begin{array}{c}\text { Areia Muito } \\
\text { Grossa a Grossa }\end{array}$ & $\begin{array}{c}\text { Areia } \\
\text { cascalhosa }\end{array}$ & $\mathrm{Q} / \mathrm{F}$ & Subangular \\
\hline 5 & Pouso & $\begin{array}{c}23^{\circ} 09^{\prime} 34.4^{\prime \prime} \\
\mathrm{S}\end{array}$ & $\begin{array}{c}044^{\circ} 08^{\prime} 19.5^{\prime \prime} \\
W\end{array}$ & $\begin{array}{c}\text { Setentrional } \\
\text { Oriental }\end{array}$ & $0.31 \mathrm{~m}$ & 3.46 & $\mathrm{E} / \mathrm{NE}$ & Plunging & $\begin{array}{l}\text { Areia Grossa a } \\
\text { Muito Grossa }\end{array}$ & Areia & $\mathrm{Q} / \mathrm{F} / \mathrm{MP}$ & Subangular \\
\hline 6 & Provetá P1 & $\begin{array}{c}23^{\circ} 10^{\prime} 48.9^{\prime \prime} \\
\mathrm{S}\end{array}$ & $\begin{array}{c}044^{\circ} 20^{\prime} 40.7^{\prime \prime} \\
W\end{array}$ & $\begin{array}{l}\text { Meridional } \\
\text { Ocidental }\end{array}$ & $\begin{array}{c}0,26- \\
0,65\end{array}$ & $\begin{array}{l}8,57- \\
10,65\end{array}$ & $\mathrm{~s}$ & $\begin{array}{c}\text { Plunging, } \\
\text { Spilling }\end{array}$ & $\begin{array}{l}\text { Areia média a } \\
\text { Fina }\end{array}$ & Areia & $\mathrm{Q} / \mathrm{F} / \mathrm{MP}$ & $\begin{array}{l}\text { Muito Angular } \\
\text { Angular }\end{array}$ \\
\hline 7 & Provetá P2 & $23^{\circ} 10^{\prime} 51.2^{\prime \prime}$ & $\begin{array}{c}044^{\circ} 20^{\prime} 31.9^{\prime \prime} \\
W\end{array}$ & $\begin{array}{l}\text { Meridional } \\
\text { Ocidental }\end{array}$ & $0,36-1,04$ & $\begin{array}{r}9,4- \\
21,65\end{array}$ & $\mathrm{~s}$ & Plunging & $\begin{array}{c}\text { Areia Grossa a } \\
\text { Média }\end{array}$ & Areia & $\mathrm{Q} / \mathrm{F} / \mathrm{MP}$ & $\begin{array}{l}\text { Muito Angular } \\
\text { Subangular }\end{array}$ \\
\hline 8 & Provetá P3 & $\begin{array}{c}23^{\circ} 10^{\prime} 56.1^{\prime \prime} \\
\end{array}$ & $\begin{array}{c}044^{\circ} 20^{\prime} 25.3^{\prime \prime} \\
W\end{array}$ & $\begin{array}{l}\text { Meridional } \\
\text { Ocidental }\end{array}$ & $0,24-0,87$ & $\begin{array}{l}7,76- \\
13,19\end{array}$ & $\mathrm{~s}$ & $\begin{array}{l}\text { Plunging, } \\
\text { Surging }\end{array}$ & $\begin{array}{l}\text { Areia Grossa a } \\
\text { Média }\end{array}$ & Areia & $\mathrm{Q} / \mathrm{F} / \mathrm{MP}$ & $\begin{array}{l}\text { Subarrendado } \\
\text { Muito Angular }\end{array}$ \\
\hline 9 & Dois Rios P1 & $\begin{array}{c}23^{\circ} 11^{\prime} 11.3^{\prime \prime} \\
\end{array}$ & $\begin{array}{c}044^{\circ} 11^{\prime} 24.8^{\prime \prime} \\
W\end{array}$ & $\begin{array}{l}\text { Meridional } \\
\text { Oriental }\end{array}$ & $0,46-1,34$ & $\begin{array}{l}8,37- \\
12,77\end{array}$ & E-SE & $\begin{array}{l}\text { Spilling, } \\
\text { Plunging }\end{array}$ & $\begin{array}{c}\text { Areia muito Fina a } \\
\text { Fina }\end{array}$ & Areia & $\mathrm{Q} / \mathrm{F} / \mathrm{MP}$ & Subangular \\
\hline 10 & Dois Rios P2 & $\begin{array}{c}23^{\circ} 10^{\prime} 58.5^{\prime \prime} \\
\mathrm{S}\end{array}$ & $\begin{array}{c}044^{\circ} 11^{\prime} 20.5^{\prime \prime} \\
W\end{array}$ & $\begin{array}{c}\text { Meridional } \\
\text { Oriental }\end{array}$ & $\begin{array}{c}0,58- \\
1,72\end{array}$ & $\begin{array}{l}8,88- \\
14,07\end{array}$ & E-SE & $\begin{array}{l}\text { Spilling, } \\
\text { Plunging }\end{array}$ & $\begin{array}{c}\text { Areia muito Fina a } \\
\text { Média }\end{array}$ & Areia & $\begin{array}{c}\mathrm{Q} / \mathrm{F} / \mathrm{MP} / \mathrm{C} \\
/ \mathrm{FC}\end{array}$ & $\begin{array}{c}\text { Subangular } \\
\text { Angular }\end{array}$ \\
\hline 11 & $\begin{array}{l}\text { Lopes Mendes } \\
\text { P1 }\end{array}$ & $\begin{array}{c}23^{\circ} 10^{\prime} 00.4^{\prime \prime} \\
\mathrm{S}\end{array}$ & $\begin{array}{c}044^{\circ} 08^{\prime} 16.0^{\prime \prime} \\
W\end{array}$ & $\begin{array}{l}\text { Meridional } \\
\text { Oriental }\end{array}$ & $0,62-1,90$ & $\begin{array}{l}11,1- \\
13,7\end{array}$ & $\mathrm{~s}$ & $\begin{array}{l}\text { Spilling, } \\
\text { Plunging }\end{array}$ & $\begin{array}{l}\text { Areia Fina a } \\
\text { Média }\end{array}$ & Areia & $\begin{array}{c}\mathrm{Q} / \mathrm{F} / \mathrm{MP} / \mathrm{C} \\
/ \mathrm{FC}\end{array}$ & $\begin{array}{c}\text { Subangular } \\
\text { Subarredondad } \\
0\end{array}$ \\
\hline 12 & $\begin{array}{l}\text { Lopes Mendes } \\
\text { P2 }\end{array}$ & $\begin{array}{c}23^{\circ} 10^{\prime} 10.4^{\prime \prime} \\
\mathrm{S}\end{array}$ & $\begin{array}{c}044^{\circ} 07^{\prime} 46.7^{\prime \prime} \\
W\end{array}$ & $\begin{array}{l}\text { Meridional } \\
\text { Oriental }\end{array}$ & $\begin{array}{c}0,64- \\
1,42\end{array}$ & $\begin{array}{l}9,65- \\
15,06\end{array}$ & S-sw & $\begin{array}{l}\text { Spilling, } \\
\text { Plunging }\end{array}$ & $\begin{array}{l}\text { Areia Fina a } \\
\text { Média }\end{array}$ & Areia & $\mathrm{Q} / \mathrm{F} / \mathrm{FC}$ & $\begin{array}{c}\text { Subangular } \\
\text { Subarredondad } \\
0\end{array}$ \\
\hline 13 & $\begin{array}{c}\text { Lopes Mendes } \\
\text { P3 }\end{array}$ & $\begin{array}{c}23^{\circ} 10^{\prime} 27.2^{\prime \prime} \\
\text { S }\end{array}$ & $\begin{array}{c}044^{\circ} 07^{\prime} 26.3^{\prime \prime} \\
W\end{array}$ & $\begin{array}{l}\text { Meridional } \\
\text { Oriental }\end{array}$ & $0,3-1,09$ & $\begin{array}{l}9,16- \\
13,77\end{array}$ & SW & $\begin{array}{l}\text { Spilling, } \\
\text { Plunging }\end{array}$ & Areia Fina & Areia & $\mathrm{Q} / \mathrm{F} / \mathrm{FC}$ & $\begin{array}{c}\text { Subangular } \\
\text { Subarredondad } \\
\text { o }\end{array}$ \\
\hline
\end{tabular}

H (m) - Altura média da onda na arrebentação, em metros; T (s) - Período médio da onda na arrebentação, em segundos.

* Composição dos sedimentos das praias: Q - Quartzo; F - Feldspato; MP - Mineral pesado; C -

Concha; FC - Fragmento de concha

${ }^{+}$Forma de arrebentação predominante observada durante os monitoramentos de campo. 
As areias quartzosas nesta praia são pobremente selecionadas e variam de grossa (85-25\%) a média (69-15\%), com presença expressiva das frações areia muito grossa (39\%) e fina (21\%) (Figura 4B). A morfoscopia dos grãos de areia indica a predominância de sedimentos muito angular (29-54\%) (Figura 4B; Tabela 1).
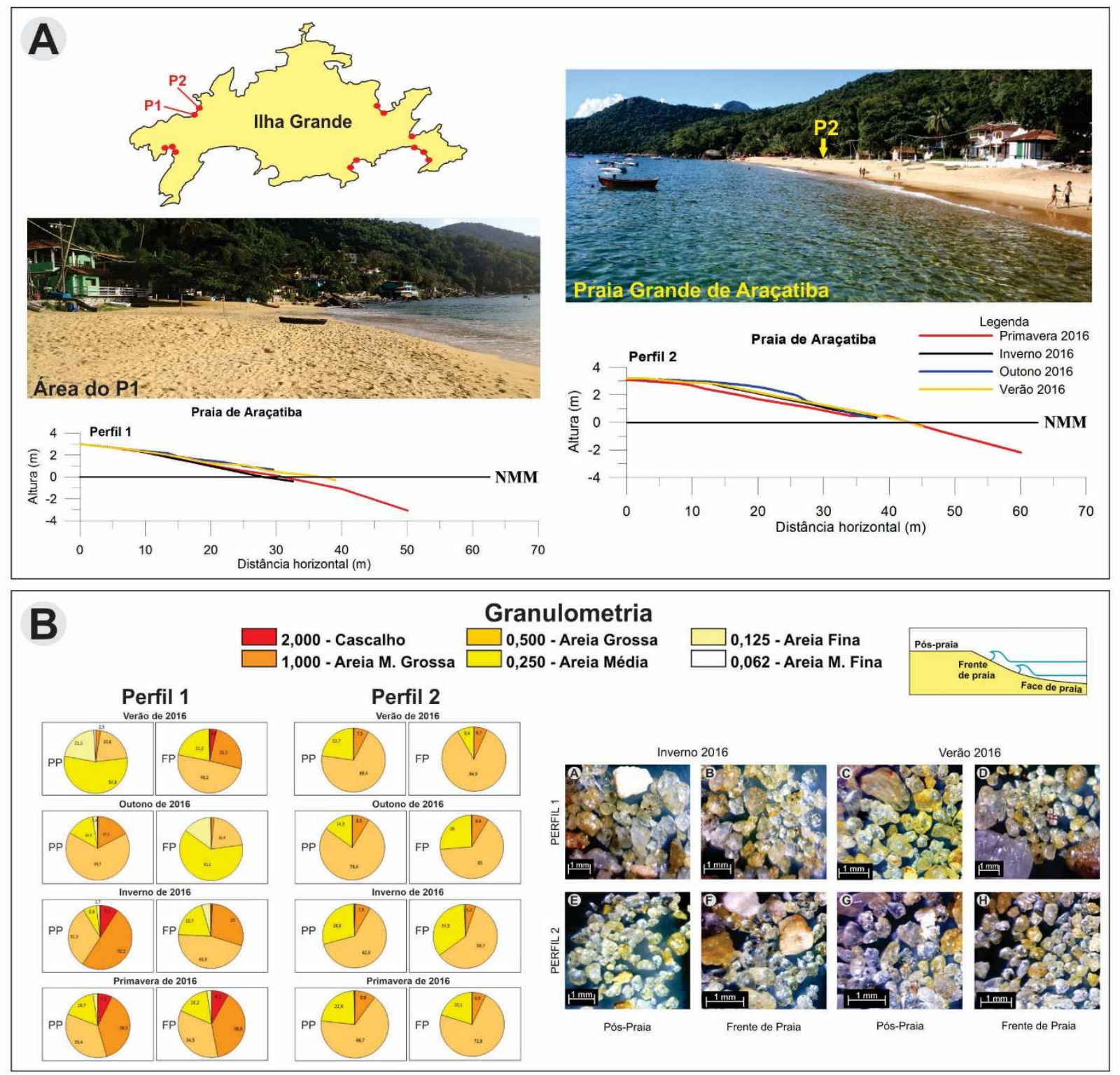

Figura 4 - Praia de Grande Araçatiba: (A) morfologia e (B) sedimentação. Fotos: Thamyres Brum (2016). NMM, nível médio do mar.

\section{Praia do Abraão}

A praia do Abraão (Figura 2B), com 1250 metros de extensão e voltada inteiramente para o canal entre a ilha e o continente, apresentou condição de 
mar predominantemente calmo, com pequenas ondulações incidindo de nordeste (Figuras 1 e 3; Tabela 1). Essas ondas arrebentam próximo à linha d'água na forma de pequenos tubos (plunging), com altura de cerca de 0,20 m, sob condição de mar calmo; o período médio da onda foi de 9,5 segundos (Tabela 1 ).

A aquisição de perfis topográficos na praia do Abraão foi realizada apenas na porção emersa, devido ao grande tráfego de embarcações na enseada e à poluição das águas neste trecho do litoral. Esta praia apresenta uma morfologia bastante estável, pela própria localização geográfica da enseada do Abraão (Figura 3), inteiramente abrigada da incidência de ondas de tempestades. 0 setor noroeste (perfil 1) de Abraão apresentou uma morfologia homogênea e um pós-praia bastante alterado pela presença de inúmeras embarcações estacionadas na faixa de areia emersa (Figura 5A). A praia exibiu uma largura média de 54 metros (Figura 5A), com variações entre 47 e $61 \mathrm{~m}$ (outono e inverno de 2014, respectivamente); essa pequena variação indica uma baixa dinâmica para este trecho do litoral de Abraão, semelhante ao que ocorre com algumas praias abrigadas na Baía de Guanabara (SILVA et al., 2016). As Ilhas do Macedo, localizadas cerca de 140-250 m da linha d'água, protegem este trecho da praia e favorecem o acúmulo de areias formando um tômbolo embrionário e uma região submarina de baixo gradiente. No setor sudeste de Abraão (perfil 2), os perfis topográficos de praia apontam para uma maior dinâmica, em comparação com o perfil 1 (Figura $5 \mathrm{~A}$ ). A frente de praia é mais íngreme (20$\left.25^{\circ}\right)$, o que pode ser facilmente percebido por uma mudança abrupta na declividade a partir da linha d'água. A largura da praia variou entre a máxima de 50 metros no inverno de 2014 e a mínima de 38 m verão de 2015 (Figura 5A). Essa dinâmica está relacionada à maior exposição deste trecho da praia às mudanças nas condições de mar e à dinâmica fluvial, devido à proximidade (15 metros) de um córrego, que secciona a faixa de areia emersa da praia (Figura $5 \mathrm{~A})$ e contribui com o aporte sedimentar. Esse córrego aumenta consideravelmente a sua largura e competência imediatamente após a ocorrência de chuvas, como constatado por ocasião dos monitoramentos (Figura 5A).

Os sedimentos da praia do Abraão são pobremente selecionados e variam consideravelmente ao longo do arco praial; apresentam areias quartzosas subangulares (90\%), com feldspatos e poucos minerais pesados (Figura 5B). Essas areias são predominantemente média (65-18\%) a grossa (60-4\%) na área 
do perfil 1 e muito grossa (86-30\%) a grossa (34-11\%) no perfil 2 (Figura 5B), evidenciando um ligeiro aumento no tamanho dos grãos para sudeste (perfil 2). Em resposta a um aumento na energia das ondas dentro da Enseada de Abraão, durante a ocorrência de ressacas, a quantidade de cascalhos e areia muito grossa tende a aumentar significativamente, como observado no inverno de 2014 (Figura 5B; Tabela 1).
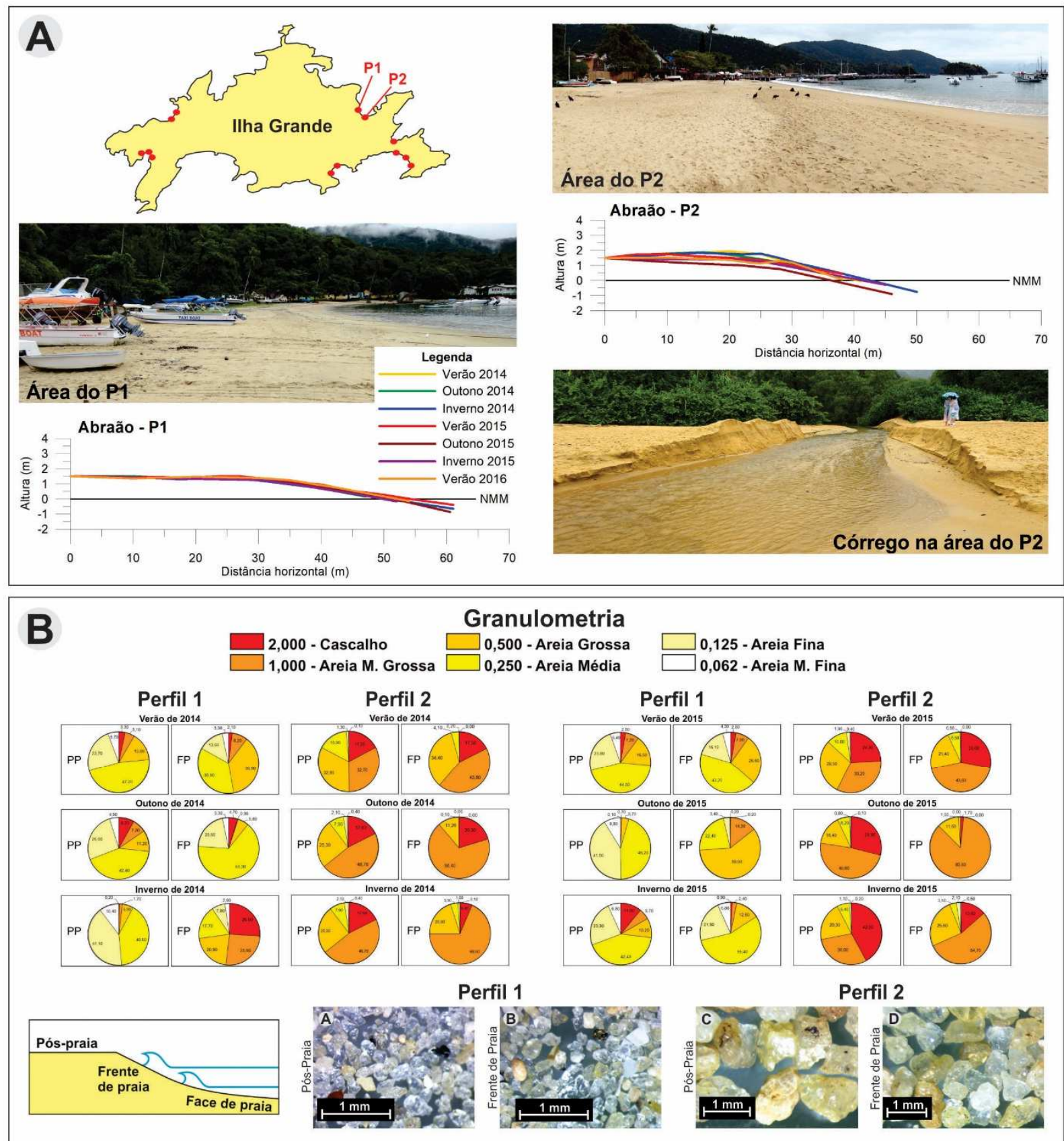

Figura 5 - Praia de Abraão: (A) morfologia e (B) sedimentação. Fotos: André Silva (2014). NMM, nível médio do mar. 
Praia de Pouso

$\mathrm{Na}$ praia de Pouso (Figura 2C), com 600 metros de extensão, a arrebentação das ondas ocorre próximo à linha d'água, devido à declividade acentuada do perfil praial. Essas ondas incidem de leste-nordeste, geralmente com baixa energia (altura média de 0,31 m na arrebentação) e período médio de 3,46 segundos (Tabela 1). Quando comparada à Enseada do Abraão, a Enseada das Palmas, onde se localiza a praia de Pouso (Figuras 1 e 3), encontra-se mais geograficamente abrigada entre promontórios rochosos (pocket beach). No entanto, este setor é mais vulnerável à incidência de ondas de tempestade que, quando combinadas com a maré alta de sizígia, promovem a inundação de toda a faixa de areia da praia (Figura 6A), como observado no verão de 2015 durante uma forte ressaca que atingiu parte do litoral fluminense e que na Ilha Grande produziu ondulações de cerca de 3 metros de altura no trecho entre as enseadas de Palmas e Abraão. Isto ocorre em função da maior proximidade com a extremidade leste da Ilha Grande, mais suscetível às tempestades, conforme Godoi et al. (2011) e Gralato (2016). A praia apresentou um perfil estreito e íngreme, com significativo aumento da declividade e variabilidade morfológica em direção à face de praia até a profundidade de 2 metros (Figura 6A).

A estreita faixa de areia emersa da praia de Pouso mede apenas 13-18 metros de largura. É comum a formação de cúspides de praia nos momentos de maior agitação do mar (Figura 6A; Tabela 1). Nessa praia, os sedimentos são mal selecionados, compostos basicamente por areias quartzosas subangular (85), grossa (88-32\%) a muito grossa (44-39\%), com ocorrência expressiva de areia média (62\%) e fina (42\%) em alguns monitoramentos (Figura 6B; Tabela 1); e aumento no tamanho dos grãos do pós-praia (areias grossa a média) para a face de praia (areias grossa a muito grossa) (Figura 6B).

\section{Setor meridional (voltado para o oceano)}

O litoral sul ou meridional da Ilha Grande (Figuras 1 e 3) possui cerca de 65 quilômetros de extensão desde a Ponta de Castelhanos (no extremo leste) até a Ponta do Acaiá (extremo oeste). Este setor abrange um total de 22 praias (BAPTISTA, 2017), incluindo as três selecionadas para este estudo. Na borda sul da ilha estão localizadas as praias mais susceptíveis à incidência direta de ondas de tempestade devido à localização, nem sempre abrigada entre promontórios 
rochosos, como é o caso das praias de Provetá, Dois Rios e Lopes Mendes, selecionadas para este estudo; além das praias do Aventureiro, do Sul, do Leste e Parnaioca (Figura 3).
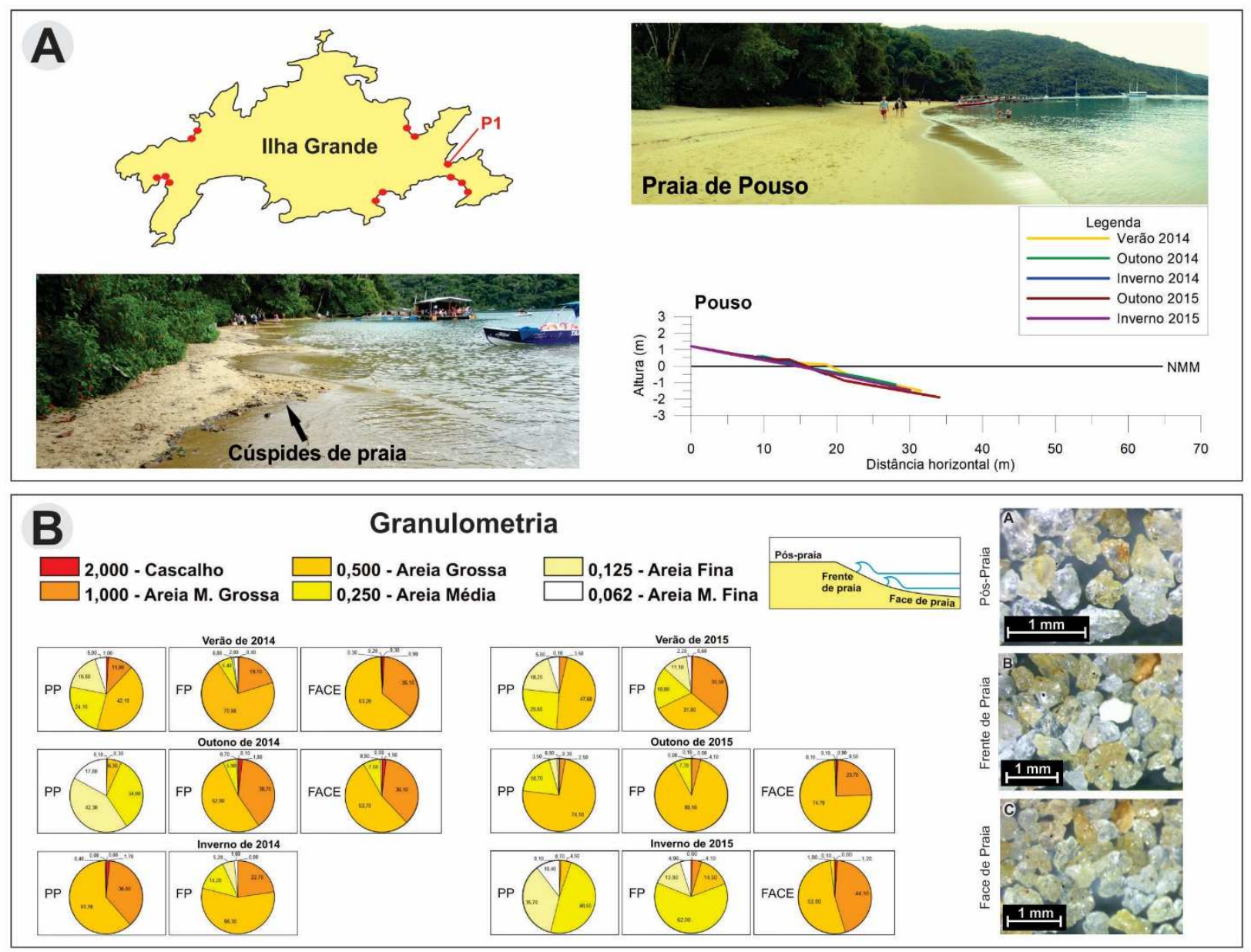

Figura 6 - Praia de Pouso: (A) morfologia e (B) sedimentação. Fotos: André Silva (2015). NMM, nível médio do mar.

\section{Praia de Provetá}

A praia de Provetá (Figura 2D), com 712 metros de extensão, está localizada no setor sudoeste da Ilha Grande, numa reentrância entre a Ponta da Pissirica e dos Meros, respectivamente (Figura 3). Neste setor da ilha, as rápidas mudanças nas condições de mar ocorrem quando grandes ondas, quase sempre provenientes de sudoeste, atingem diretamente a praia de Provetá. A altura das ondas na arrebentação pode variar bastante, desde poucos centímetros a alguns metros; a altura mínima foi de apenas 0,2 m (outono de 2016) sob condição de mar calmo e a máxima em torno de 1 m (inverno de 2016) sob condição de 
tempestade (Tabela 1). O período médio das ondas variou entre 7,76 e 21,65 segundos. Essas ondas, com arrebentação do tipo Plunging e Spilling (Tabela 1), formam vigorosas correntes de retorno, mais marcantes no meio do arco praial.

Os perfis topográficos de praia em Provetá foram realizados em três locais distintos: perfil 1, setor noroeste; perfil 2, no meio do arco praial; e perfil 3, no extremo sudeste (Figura 3). O setor noroeste (perfil 1) da praia apresentou uma dinâmica moderada, quando comparada às demais áreas (Figura 7A). Exibe um perfil em rampa com cerca de $17^{\circ}$ de inclinação e ligeira diminuição da declividade em direção à face de praia. A largura média da praia emersa corresponde a 28 metros, entre o mínimo de 24,5 m (verão de 2016) e a máxima de $34 \mathrm{~m}$ (outono de 2016). O meio do arco praial (perfil 2) é semelhante ao perfil 1, com uma dinâmica moderada e mesma largura média desde o início da praia até a linha d'água (Figura 7A). O pós-praia exibe uma berma discreta, seguida por uma frente de praia mais íngreme, com cerca de $19^{\circ}$ de inclinação para o mar. O setor sudeste de Provetá (perfil 3) é o mais dinâmico e também o mais estreito (parte emersa); apresentou as maiores variações morfológicas em comparação com as demais áreas; com uma largura média de apenas 20 metros até a linha d'água, variou entre 19 m (verão de 2015) e 25 m (outono de 2016) (Figura 7A). A destruição de uma berma formada no outono de 2016 é acompanhada por um estreitamento do perfil praial nas estações seguintes (inverno e primavera de 2016). Na primavera de 2016, tal como no perfil 1, foi realizado um perfil topobatimétrico, com $54 \mathrm{~m}$ de extensão desde o limite interno da praia até a porção submarina. Constatou-se uma mudança na declividade entre a porção emersa - cerca de $20^{\circ}$ de inclinação - para a face de praia, que apresenta um canal e um perfil ligeiramente inclinado para o mar (perfil 3; Figura 7A).

As areias quartzosas nesta praia exibem um alto grau de angularidade (28-66\% muito angular), apresentam baixo selecionamento e variam bastante em tamanho (Figura 7B). Areia média (47-27\%) e fina (63-22\%) são predominantes na área do perfil 1 ; aumentando progressivamente em direção aos perfis 2 e 3, onde predominam areias grossa (64-30\%) e média (57-26\%), com presença de areia muito grossa, principalmente no inverno de 2016 (4927\%) (Figura 7B; Tabela 1). 

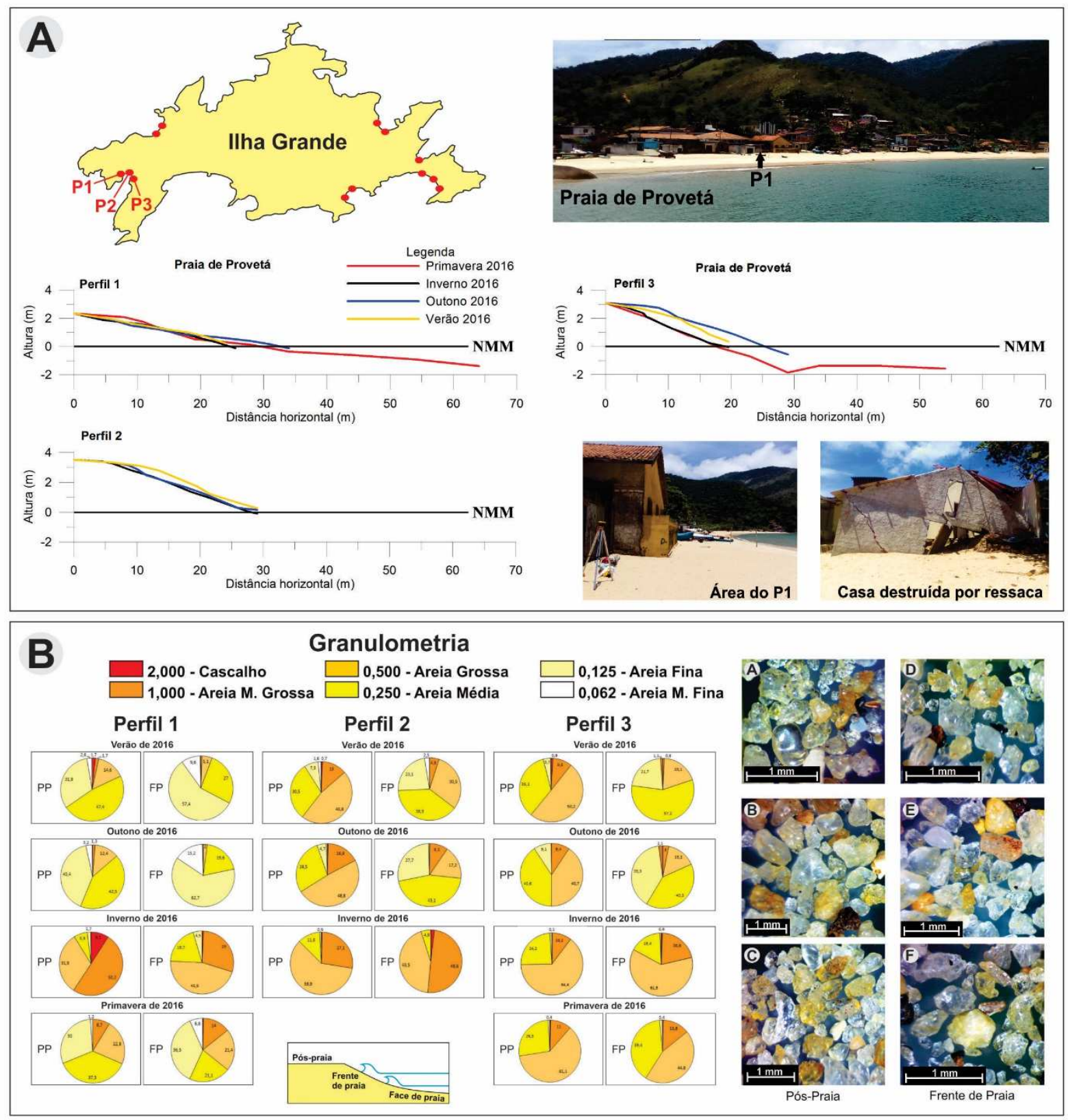

Figura 7 - Praia de Provetá: (A) morfologia e (B) sedimentação. Fotos: André Silva (2016). NMM, nível médio do mar.

\section{Praia de Dois Rios}

O litoral de Dois Rios (Figura 2E), com 1.200 metros de extensão, exibe condições de mar variáveis, onde predomina uma dinâmica moderada. Em meio a uma ampla zona de surf, as ondas incidem preferencialmente dos quadrantes leste e sudeste, e arrebentam nas formas spilling e plunging em diferentes locais, em decorrência da baixa declividade do fundo, conforme Laing (1998). A altura média das ondas na arrebentação oscilou entre 0,46 m (verão de 2014) e 1,72 m (inverno de 2015); com períodos entre 8,37 segundos (outono de 2015) 
e 14,07 segundos (verão 2014) (Tabela 1). A altura das ondas é ligeiramente superior no setor nordeste (perfil 2) da praia, em comparação com a extremidade sul (perfil 1), como resultado da proteção exercida pelo embasamento cristalino no setor sul, interceptando as ondas de tempestade, que em boa parte do litoral fluminense são oriundas dos quadrantes sul e sudoeste (MUEHE 1979; SILVA et al., 2008; SILVA et al., 2009; SILVA et al., 2014b; PARDAL, 2009).

O perfil 1 (Figura $8 \mathrm{~A}$ ), com morfologia em rampa e cerca de $12-15^{\circ}$ de inclinação para o mar, apresentou alterações desde o limite mais interno no póspraia até a área mais externa da arrebentação; variações expressivas na linha d'água ocorrem diariamente em decorrência da baixa declividade do perfil praial, combinada às oscilações da maré. A faixa de areia emersa da praia mede cerca de 25 metros, variando entre 20 m (outono de 2015) e 46 m (outono de 2014). O perfil 2 (Figura $8 \mathrm{~A}$ ), no meio do arco de praia é mais dinâmico quando comparado ao perfil 1. A largura da faixa de areia emersa da praia, em torno de 30 metros, é superior à do perfil 1 nas mesmas condições de maré; podendo chegar a $70 \mathrm{~m}$ na maré baixa de sizígia.

A sobreposição dos perfis topobatimétricos mostra um perfil suave e côncavo, com $12-18^{\circ}$ de inclinação, porém dinâmico; variações na altura do póspraia e região submarina em torno de $1,5 \mathrm{~m}$ foram registradas em diferentes momentos a partir do outono de 2015, e pode ser percebida também na área do perfil 1 (Figura $8 \mathrm{~A}$ ). Essa diferença aponta para uma maior retirada de sedimentos neste período em resposta a um aumento médio na energia das ondas, remobilizando sedimentos da praia para a face litorânea (shoreface). Portanto, a mobilização de sedimentos em Dois Rios parece mais eficaz entre a praia e a face litorânea; e pela influência dos rios localizados nas extremidades do arco praial (Figura 8A), que contribuem com o aporte de sedimentos para esta enseada. Durante as tempestades, as ondas de maior energia tendem a alcançar a vegetação no limite com a praia, formando uma discreta escarpa de tempestade, como ocorrido no inverno de 2015 (Figura 8A). Em caso de tempestades extremas, as ondas de grande energia alcançam as áreas de vegetação à retaguarda da praia, causando inundações momentâneas. 


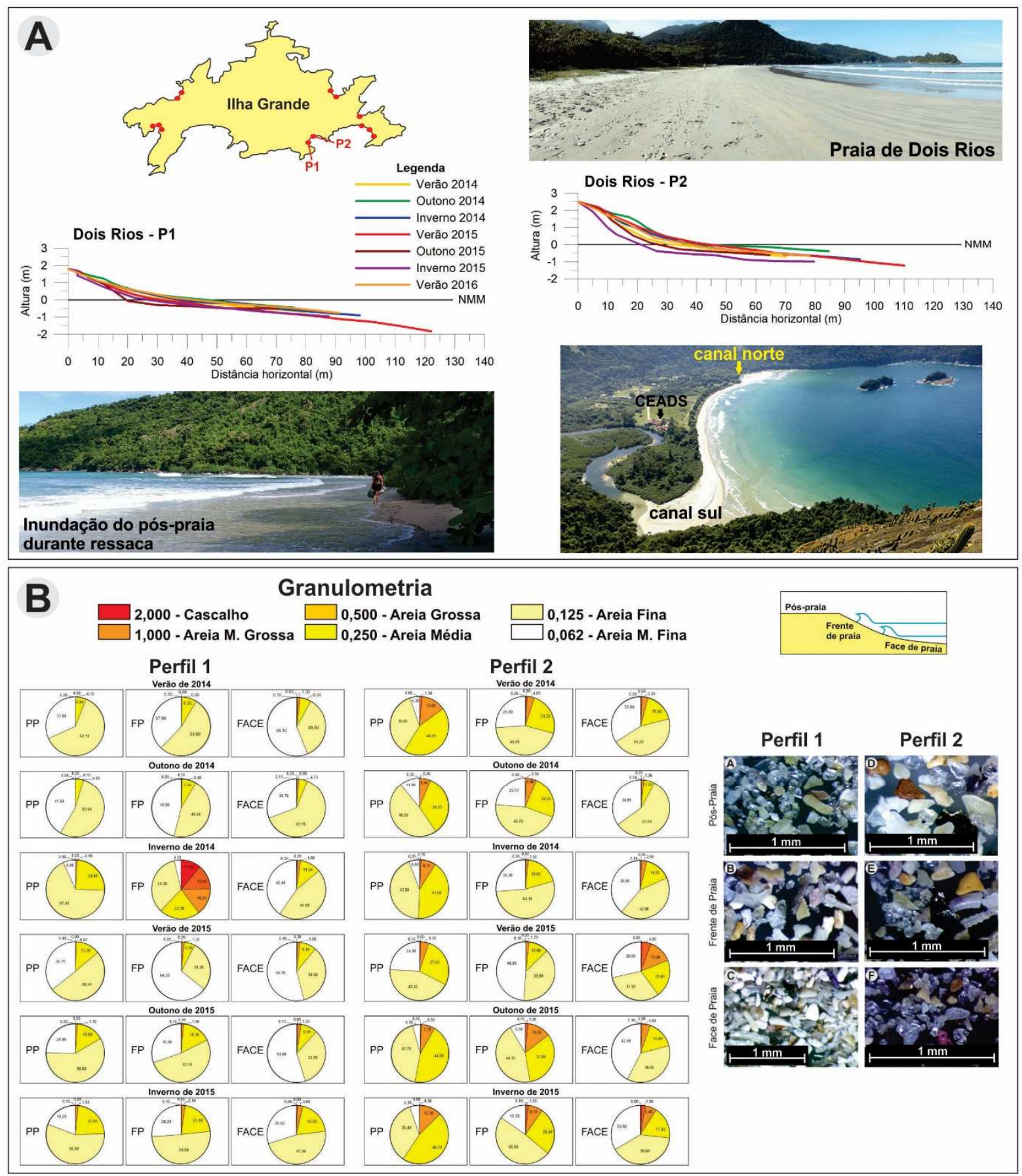

Figura 8 - Praia de Dois Rios: (A) morfologia e (B) sedimentação. Fotos: André Silva (2016). NMM, nível médio do mar.

As areias são basicamente quartzosas, com feldspatos, poucos minerais pesados, conchas e fragmentos de conchas de tamanhos variados; e bem selecionadas, com ligeira diminuição no tamanho dos grãos do perfil 1 para o perfil 2; e da porção emersa para a região submarina (Figura 8B). Areia fina (67$28 \%$ ) a muito fina (64-25\%) são predominantes; com aumento da fração areia 
muito fina na porção submersa, sendo predominante no verão de 2014 e 2015 (Figura 8A; Tabela 1), resultado de condições de mar bastante calmo, típico desta estação. A morfoscópica aponta para diferenças entre os grãos analisados, que variam entre subangulares (48-75\%) e angulares (25\%) (Figura 8A; Tabela $1)$.

\section{Praia de Lopes Mendes}

Em Lopes Mendes (Figura 2F) foram verificadas as maiores diferenças nas condições de mar por ocasião dos monitoramentos, ao longo dos 2.430 metros do arco praial e entre as estações do ano. O extremo noroeste (área do perfil 1) e meio do arco praial (perfil 2) são mais suscetíveis às variações nas condições de mar, em detrimento do setor sudeste (perfil 3), onde predominaram condições de mar calmo. A incidência de ondas nesta praia provém dos quadrantes sul e, principalmente, de sudoeste. A arrebentação das ondas ocorre nas formas spilling e plunging; com altura média entre 0,30 m e 1,90 m e período mínimo de 9,16 s e máximo de 15,06 s (Tabela 1). O meio do arco praial (perfil 2) chama a atenção pela presença de uma vigorosa corrente de retorno em quase todos os monitoramentos, motivo pelo qual este trecho da praia se encontra quase sempre interditado para o banho de mar. Verificou-se a presença de uma forte corrente de deriva litorânea para noroeste (no outono de 2015) e para sudeste (inverno de 2015).

Os resultados apontam para uma dinâmica acentuada e distinta ao longo da praia, mais intensa na extremidade noroeste (perfil 1) e no meio do arco praial (perfil 2) (Figura 9A). Quando comparada às demais praias estudadas, Lopes Mendes foi a que se apresentou mais dinâmica e, consequentemente, mais sujeita a rápidas mudanças decorrentes de alterações nas condições hidrodinâmicas. O setor noroeste (área do perfil 1) da praia é o mais frequentado pelos turistas, devido à proximidade com a trilha que permite o acesso à praia. 0 único posto de salvamento do Corpo de Bombeiros em Lopes Mendes se encontra localizado neste trecho, constantemente interditado por conta da formação de correntes que oferece risco para os banhistas. No perfil 1, a largura da faixa de areia emersa da praia variou entre $45 \mathrm{~m}$ e $72 \mathrm{~m}$; apresenta bermas no póspraia, mais proeminentes no verão, resultado de uma acreção vertical que alcança 1,5 m neste trecho; o perfil submerso exibe uma declividade moderada, 
com presença eventual e discreta de barras e canais paralelos à linha d'água, como observado no outono de 2014 (Figura 9A). O meio do arco praial (perfil 2) é o que mais preocupa devido à largura reduzida deste trecho (cerca de $40 \mathrm{~m}$ ), quando comparado aos demais (Figura 9A), o que o torna mais vulnerável à ação direta das ondas de tempestade. O pós-praia é estreito e exibe uma declividade moderada (20-220 de inclinação), com bermas discretas (verão de 2014 e 2015). A dinâmica morfológica neste trecho é marcada por grandes diferenças verticais entre os perfis, que chegam a quase 2 metros entre as estações, evidenciando um rebaixamento do perfil nos meses de inverno, tornando-os mais côncavos; seguido, por uma fase de recuperação no verão, quando ocorre um crescimento vertical devido ao acúmulo de sedimentos nessas áreas (Figura 9A). Esse comportamento segue uma tendência normal de engordamento e estreitamento das praias formando, respectivamente, perfis típicos de tempo bom e de tempestade (CARTER, 1988; DAVIS, 1985; DAVIS e FITZGERALD, 2004). A porção submarina da praia apresenta barras e canais paralelos e perpendiculares à linha d'água; alguns desses canais podem alcançar 50 metros de largura e evidenciam o importante papel das correntes de retorno no transporte de sedimentos perpendicularmente ao litoral.

O setor leste (perfil 3) apresenta variações mais discretas, quando comparado aos perfis 1 e 2 (Figura 9A). As maiores alterações foram registradas na porção emersa da praia, que mede cerca de $70 \mathrm{~m}$ de largura e apresenta um pós-praia fortemente influenciado pela dinâmica de erosão e deposição de sedimentos provenientes de um canal fluvial, que secciona o perfil praial emerso em várias direções (Figura 9A), de forma esporádica e sempre que alimentado pela precipitação local. Bermas são comuns no pós-praia e aparecem associadas com feições de corte (escarpas) resultantes da erosão fluvial. Essa erosão tem causado a exposição de raízes e tombamento de árvores no limite interno da praia. O perfil submarino é suave e pouco dinâmico; caracteriza-se por uma baixa variação morfológica (Figura 9A), devido à proteção exercida pela Ponta do Lopes Mendes (Figura 3). Este trecho é o único utilizado por embarcações de pequeno e médio porte. Apesar da aparente estabilidade, durante a ocorrência de eventos de elevada magnitude, grandes ondas de tempestades alcançam este trecho do litoral; e foram responsáveis por deixar sobre o pós-praia uma boia de ferro com quase 2,5 metros de diâmetro. 

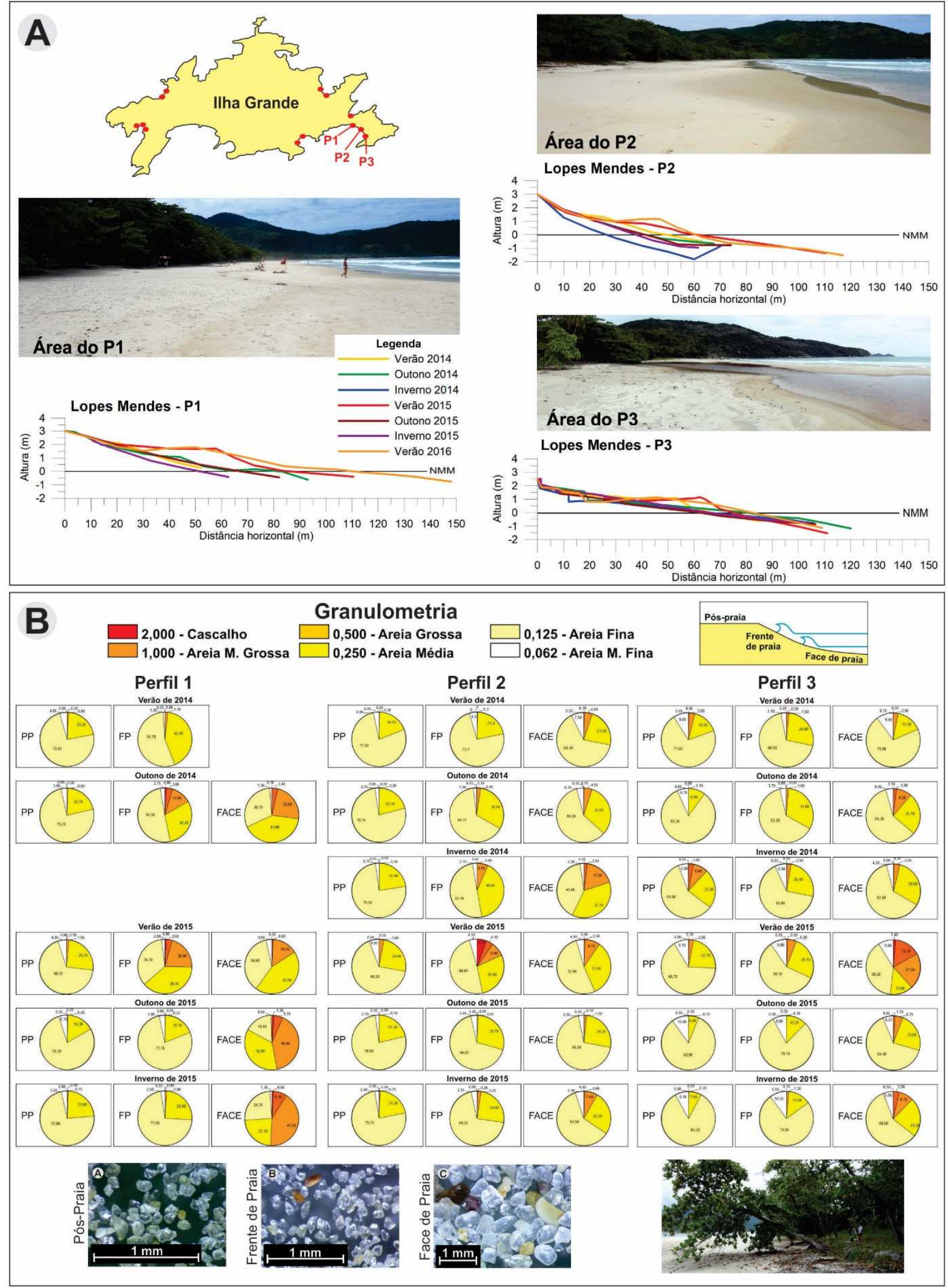

Figura 9 - Praia de Lopes Mendes: (A) morfologia e (B) sedimentação. Fotos: André Silva (2015). NMM, nível médio do mar. 
A praia de Lopes Mendes apresentou uma diminuição discreta no tamanho dos grãos de nordeste (perfil 1) para sudeste (perfil 3); e um aumento do tamanho dos grãos da porção emersa para a submarina (exceto no perfil 3), com concomitante diminuição no grau de selecionamento do pós-praia para a face de praia (Figura 9B; Tabela 1). Nos perfis 1 e 2 predominam areias quartzosas, subangulares (40-72\%) a subarredondadas (28-45\%), variando de fina (78$34 \%$ ) a média (42-16\%) no pós-praia e frente de praia; areia média (44\%) e grossa (42\%) aparecem em maior quantidade na face de praia (Figura 9B; Tabela 1). No perfil 3, os sedimentos são em geral subangulares, bem selecionados e representados em grande parte pela fração areia fina (84-39\%), com aumento expressivo na quantidade de areia muito fina (10\%), o que evidencia uma ligeira diminuição no tamanho dos grãos em direção a esta extremidade do arco praial (Figura 9B; Tabela 1).

\section{DISCUSSÃO}

As praias do litoral da Ilha Grande apresentam diferentes níveis de exposição aos eventos de tempestade, determinados pela sua localização e orientação. As praias de Grande Araçatiba (Figura 4), Abraão (Figura 5) e Pouso (Figura 6), voltadas para o continente, exibem uma dinâmica variando entre baixa e moderada, em resposta às mudanças nas condições de mar. Nessas praias, o tráfego de embarcações é intenso, devido a sua ampla utilização nas atividades ligadas ao turismo na ilha, o que aumenta o risco de acidentes durante a ocorrência de ressacas (BAPTISTA, 2017). A localização dessas praias, todas voltadas para o continente (Figuras 1 e 3), é o fator determinante na dinâmica morfológica e das características dos seus materiais. Apesar de abrigadas e quase sempre sujeitas a uma baixa energia, praias com essas características também podem ser atingidas por ondas de tempestades, como ocorre com algumas praias na Baía de Guanabara (SILVA et al., 2016) e na praia de Jabaquara na Baía de Paraty (PINHEIRO et al., 2019). As ressacas causam preocupações mesmo em praias abrigadas, pois podem promover o rompimento de tubulações, destruição de casas e de outros bens; tais problemas são comuns nas praias de Icaraí e Flechas em Niterói (SILVA et al., 1999) e na praia do Flamengo no Rio de Janeiro (SILVA et al., 2016). Esse ambiente tende a ser mais modificados que as praias oceânicas, pois apresenta baixa energia 
hidrodinâmica, o que favorece a introdução de obras de engenharia junto às praias abrigadas, conforme destaca Nordstrom (1989).

A praia de Grande Araçatiba, no setor noroeste da ilha, apresenta vulnerabilidade baixa à moderada, frente à incidência de ondas de tempestade (Figura 4A). Apesar disso, as casas e restaurantes localizados no limite interno do pós-praia são eventualmente afetados pelas ondas durante eventos de maior magnitude. O tráfego de embarcações é intenso nessa praia, pois a mesma se constitui em uma das alternativas para almoço, realizada diariamente por inúmeras embarcações que partem de Abraão, pela manhã, para diversos locais na ilha. A baixa maturidade observada nos sedimentos da praia de Grande Araçatiba, representada em grande parte por areia grossa, com arredondamento variando entre subangular, angular e bem angular (Figura 4B), é comum em litorais abrigados e sujeitos à oferta de materiais a partir de rios locais (FRIEDMAN e SANDERS, 1978; NORDSTROM, 1989). Essas características evidenciam a contribuição do aporte fluvial na sedimentação das praias estudadas e são importantes para se investigar as fontes de materiais para esses ambientes.

A praia de Abraão apresentou baixa dinâmica, mas se mostrou vulnerável à incidência das ondas de tempestade, ligeiramente distinta entre as áreas monitoradas. O perfil 1 (Figura 5A) está mais abrigado e, consequentemente, protegido das ressacas, provavelmente devido à proteção exercida pelas Ilhas Macedo (Figura 3), que interceptam boa parte das ondas que chegam neste trecho do litoral. O perfil 2 (Figura $5 \mathrm{~A}$ ), onde está localizado o píer principal para embarque e desembarque de passageiros, apresentou-se mais exposto à incidência de ondas de tempestade, o que representa um risco para o tráfego de embarcações, para o funcionamento dos restaurantes localizados muito próximo ou mesmo dentro do pós-praia, entre outros. A praia de Abraão é formada por sedimentos que variam consideravelmente em tamanho, entre as estações do ano e em ambos os trechos monitorados (Figura 5B). O predomínio de areia média no perfil 1 e areia muito grossa no perfil 2 mostra um aumento no tamanho médio dos grãos de noroeste para sudeste (Figura 5B). Trata-se de um material basicamente quartzoso, com grãos subangulares e com poucos feldspatos; a granulometria, bastante heterogênea, aponta para um baixo selecionamento (Figura 5B). Essas características são o resultado da interação 
das ondas e marés com a descarga fluvial de caráter intermitente. O aporte fluvial de materiais na sedimentação da praia para este trecho da Enseada do Abraão é mais eficaz nos meses de verão, que concentram as chuvas torrenciais da região, conforme Salgado et al. (2007).

A praia de Pouso apresentou uma dinâmica moderada e mostrou-se vulnerável à incidência de ondas de tempestade, ainda que esteja abrigada entre promontórios rochosos e voltada para o continente (Figura 5A). Este resultado corrobora com estudo realizado por Godoi et al. (2011), que aponta para a entrada de ondas de alta energia na Enseada de Palmas, com base em um simulador de propagação de ondas. A faixa emersa de areia da praia, que se manteve sempre estreita (cerca de 15 metros), desapareceu totalmente no monitoramento realizado no verão de 2015 (Figura 5A), em resposta à interação entre as ondas de tempestade e a preamar. As ressacas, neste caso, representam uma ameaça às atividades náuticas realizadas nesta praia, que funciona como entreposto para o acesso à praia de Lopes Mendes. Embarcações de pequeno e médio porte realizam o transporte diário de algumas centenas e/ou milhares de pessoas entre a Vila de Abraão e a Enseada de Palmas. Durante a ocorrência de ressacas foram observadas ondas de tempestade com altura superior a 3 metros nas proximidades da Ponta Grossa, entre as enseadas de Abraão e Palmas. Na praia de Pouso, as areias aumentam de tamanho do póspraia (areia grossa a média) para a face de praia (areias grossa a muito grossa); as maiores variações foram observadas no pós-praia, que apresentou areia grossa (maioria dos monitoramentos), média (inverno de 2015) e fina (outono de 2014) (Figura 5A). O grau de selecionamento aumenta em direção à face de praia, onde areia grossa a muito grossa, bem selecionadas, representam a quase totalidade dos materiais presentes na porção submarina (Figura 5A). Os sedimentos predominantemente quartzosos, com poucos feldspatos, e subangulares, sugerem um baixo grau de maturidade destas areias, possivelmente pela proximidade da área-fonte, representada em grande parte pelos costões e vertentes da ilha.

As praias de Provetá (Figura 7), Dois Rios (Figura 8) e Lopes Mendes (Figura 9), voltadas para o oceano, apresentaram uma dinâmica mais acentuada. A praia de Lopes Mendes foi a que apresentou maior exposição e vulnerabilidade à incidência de ondas de tempestade (Figura 9). As tempestades de maior 
magnitude promovem rápidas mudanças na morfologia dessas praias, alcançam o limite interno do pós-praia e removem grande quantidade de sedimentos, arrancando a vegetação rasteira, expondo as raízes das árvores e, eventualmente, derrubando algumas delas (Figura 9B); em Provetá, essas ondas têm causado danos em algumas construções localizadas próximo ou mesmo dentro dos limites da praia (Figura 7A). Os impactos e danos causados pelas ondas de tempestade nas praias estudadas tendem a ser mais intensos nas áreas de maior exposição, com destaque para o setor nordeste de Dois Rios (Figura 8A), o meio do arco e o setor noroeste de Lopes Mendes (Figura 9A) e o setor sudeste de Provetá (Figura 7A).

O perfil 1 da praia de Provetá apresentou-se menos instável, quando comparado aos perfis 2 e 3 (Figura 7A), devido à localização mais abrigada e pela proteção parcial exercida pela Ponta da Pissirica (Figura 3). Neste mesmo local, está localizado um píer (cerca de $1 \mathrm{~km}$ do perfil 1) para embarque e desembarque diário de mercadorias diversas e passageiros provenientes principalmente da cidade de Angra dos Reis. Na área dos perfis 2 e 3 (Figura 7A), a dinâmica é mais acentuada devido à maior incidência de ondas de tempestade. As tempestades de maior magnitude promovem rápidas mudanças na morfologia desta praia, alcançam o limite interno do pós-praia, diminuindo consideravelmente a largura da mesma (Figura 7A). Essas ondas também podem causar inundações nas áreas localizadas à retaguarda deste ambiente, oferecendo risco para as casas, camping e bares, como ocorrido na primavera de 2016. A exposição de raízes de árvores e os danos nas construções observados (Figura 7A), podem estar relacionados à ocorrência de um processo erosivo neste arco praial, com base em indicadores de erosão apontados por Bird (2008) e Souza (2009).

O litoral de Dois Rios apresentou uma vulnerabilidade à incidência de ondas de tempestade distinta ao longo do arco praial (Figura 8A): o perfil 1, no setor sul, apresentou-se menos vulnerável, quando comparado ao perfil 2 mais ao norte. A menor vulnerabilidade às ondas de tempestade no setor sul de Dois Rios deve-se à proteção exercida pelo costão, que impede que parte das ondas de tempestade vindas dos quadrantes sul e sudoeste atinjam diretamente este trecho do litoral. No entanto, ondas de tempestade podem eventualmente atingir a praia e inundar áreas localizadas na retaguarda deste ambiente, oferecendo 
risco para as instalações do CEADS (o que já ocorreu anteriormente, conforme relatado por alguns funcionários). A presença de uma discreta escarpa de tempestade com concomitante evidência de ação destrutiva sobre a vegetação rasteira foi observada em toda a extensão da praia no inverno de 2015. O perfil 2, mais ao norte, é mais dinâmico e vulnerável às ressacas (Figura 8A). Este setor da praia sofreu as maiores variações morfológicas, devido à sua localização (meio do arco praial) e a consequente exposição à incidência direta de ondas vindas de várias direções. A presença de areias fina, muito fina e média, com grau de arredondamento variando entre subangular a arredondado (Figura 8B), aponta para diferentes níveis de retrabalhamento e/ou origem dos sedimentos na praia de Dois Rios. Tal característica pode estar relacionada a duas fontes principais de sedimentos: (1) fluvial, por meio do qual as areias mais angulares são trazidas pelos canais Barra Grande (sul) e Barra Pequena (norte) (Figura 8A); (2) plataforma continental interna, de onde as areias mais arredondadas são remobilizadas (maior tempo de retrabalhamento) pela dinâmica de ondas construtivas na direção da face litorânea e praia, sendo então incorporadas a mesma. Estudos realizados por Mahiques (1987) e Medeiros (2006) apresentaram mapas dos sedimentos de fundo da Baía da Ilha Grande e apontam para a predominância de areia grossa no litoral adjacente à Enseada de Dois Rios, contrastando com a granulometria atual da praia (areia fina a muito fina - Figura 8B). Oliveira et al. (2014), após a realização de um mapeamento dos sistemas de drenagem em Dois Rios, apresenta os perfis longitudinais dos canais e chama a atenção para a presença de sedimentos finos associados ao canal meandrante. A proximidade da praia com a área-fonte e a baixa declividade da porção inferior dos canais na estreita planície costeira são características que apontam para uma maior eficiência do aporte fluvial no transporte de areias finas e muito finas para a praia. Os sedimentos mais grossos, neste caso, não chegam até a praia, ficando retidos nas porções intermediária e superior dos córregos (com base na declividade dos perfis longitudinais), devido à baixa competência destes.

O litoral de Lopes Mendes é o mais dinâmico dentre as praias estudadas (Figura 9A) e também o mais vulnerável a incidência de ondas de tempestade, que podem ultrapassar $3 \mathrm{~m}$ de altura na arrebentação. A presença de uma escarpa de tempestade no limite interno da praia, com exposição de raízes e 
árvores tombadas (Figura 9A), expõe a fragilidade da praia às ressacas e à erosão costeira. As áreas dos perfis 1 e 2 são mais dinâmicas, com destaque para o meio do arco praial (perfil 2), devido a largura reduzida da faixa de areia emersa (40 m), quando comparado aos demais perfis (Figura 9A). A existência de um pós-praia estreito, a exposição de raízes ou a remoção da vegetação são apontados em diversos estudos como indicadores de erosão costeira (BIRD, 2008; SOUZA, 2009; SOUZA e LUNA, 2009). A dinâmica fluvial atua de forma eficaz através da migração do canal, e parece ser responsável pela exposição de raízes e derrubada de árvores no limite interno da praia na área do perfil 3, causando uma intensa remoção de sedimentos neste trecho do litoral (Figura 9A). O predomínio da fração areia fina, com grau de arredondamento entre subangular a subarredondado (Figura 9B), ao longo dos 2,5 quilômetros do arco praial de Lopes Mendes, sugere que esses materiais tenham se originado, em grande parte, de uma mesma fonte. Em se tratando de uma praia oceânica e, consequentemente, sujeita a incidência direta de ondas de alta energia, esperava-se encontrar uma representatividade maior de sedimentos mais grossos (areia média, grossa, muito grossa e mesmo pequenos cascalhos), a exemplo do que ocorre em algumas praias de alta energia no litoral fluminense, como em Maricá (SILVA et al., 2008a; SILVA et al., 2014a,b) e Niterói (SILVA et al., 2004; SILVA et al., 2009). Essas características podem estar associadas a um suprimento sedimentar predominantemente fluvial, por meio do qual as areias finas são trazidas por pequenos rios locais; sem desprezar o papel da plataforma continental interna. A estreita planície costeira de Lopes Mendes recebe sedimentos de cinco pequenos riachos, com sistemas de drenagem bastante incipientes, sendo o mais expressivo localizado na área do perfil 3 (Figura 9B). No entanto, boa parte dos materiais trazidos por esses riachos parecem ficar aprisionados à retaguarda da barreira arenosa, com exceção do canal localizado no perfil 3, que secciona a faixa de areia da praia durante a ocorrência de fortes chuvas. Os sedimentos de fundo da Baía da Ilha Grande, na área adjacente ao litoral de Lopes Mendes, como já ressaltado, são constituídos basicamente por areias grossas (Mahiques, 1987; Medeiros, 2006), contrastando com a areia fina da praia. Uma outra hipótese a ser considerada é que essas areias finas podem ter sido originadas a partir da erosão de antigas dunas 
formadas em uma planície costeira mais larga e sob condição de nível do mar mais baixo que o atual.

\section{Considerações Finais}

As praias da Ilha Grande apresentam características geográficas e geomorfológicas bem distintas. Elas podem variar de centenas de metros (predominam pequenas praias encaixadas entre os costões - pocket beaches) como é o caso das praias de Pouso e Provetá, até alguns quilômetros, como a praia de Lopes Mendes. Essas praias apresentam diferentes níveis de exposição à incidência de ondas e aos eventos de tempestade, dependendo da localização e orientação das mesmas. As condições de mar no litoral da Ilha Grande mudam rapidamente em resposta à passagem eventual de frentes frias provenientes do sul do país, causando grandes agitações na superfície oceânica com a aproximação de ondas de tempestade.

As praias abrigadas localizadas na borda norte da Ilha Grande, voltadas para o continente (Grande Araçatiba, Abraão e Pouso), apresentaram uma variabilidade topográfica baixa a moderada e, consequentemente, uma menor dinâmica em comparação com as praias voltadas para o oceano. Porém, mostraram-se vulneráveis à incidência de ondas de tempestade, com destaque para o setor sudeste de Abraão (perfil 2) e Pouso. Durante a ocorrência de ressacas, as ondulações tendem a alcançar inclusive aquelas áreas normalmente mais abrigadas da ação das ondas, podendo oferecer riscos para a navegação e danos nas estruturas costeiras. Nessas áreas, o tráfego de embarcações de pequeno e médio porte é intenso, devido à sua ampla utilização nas atividades ligadas ao turismo na Ilha Grande, o que aumenta o risco para a navegação durante a ocorrência de ressacas. No litoral voltado para o oceano, as ondas de tempestade alcançam $3 \mathrm{~m}$ de altura ou mais na arrebentação, como observado no inverno de 2014 em Lopes Mendes. Essas ondas promovem rápidas mudanças na morfologia praial, alcançam o limite interno da praia e removem sedimentos, expondo as raízes das árvores e, eventualmente, derrubando algumas delas. Esta praia também foi a que apresentou maior dinâmica morfológica e sedimentar. Ela apresenta forte corrente de deriva litorânea para oeste no meio do arco praial, formando extensos canais na face de praia. A presença de canais 
perpendiculares em toda a extensão da praia evidencia a presença de vigorosas correntes de retorno.

A dinâmica sedimentar é caracterizada pela grande mobilidade de sedimentos entre a parte emersa e submersa e, no caso de Lopes Mendes e Dois Rios, ao longo das mesmas em resposta a ação da corrente de deriva litorânea e rápidas mudanças na morfologia praial. A textura dos sedimentos varia bastante entre as praias estudadas, com o predomínio de areia quartzosa fina a muito fina, subangular a subarredondada, nas praias oceânicas de Dois Rios, Lopes Mendes e Provetá; e areia média, grossa a muito grossa, subangular, nas praias de Abraão, Pouso e Grande Araçatiba, voltadas para o continente. O aporte sedimentar fluvial é expressivo para a maioria das praias da Ilha Grande. Os riachos e pequenos canais presentes na Ilha Grande são alimentados por um regime de chuvas tropicais concentradas nos meses de verão. As variações granulométricas observadas nas areias das praias são resultantes da influência dos processos costeiros e fluvial em cada ambiente e ao papel das áreas-fonte (pequenos rios e plataforma continental interna).

As praias da Ilha Grande são praticamente desconhecidas no tocante à geomorfologia. O conhecimento das características físicas das praias é fundamental para a compreensão da dinâmica costeira e, consequentemente, da vulnerabilidade aos eventos de tempestades e riscos de erosão neste litoral. 0 forte crescimento do turismo na Ilha Grande, com um número cada vez maior de embarcações transportando turistas entre o continente e a ilha, assim como, da Vila de Abraão em direção às principais praias e ilhas da região, a construção de obras de engenharia dentro dos limites da praia (em Abraão, Provetá e Grande Araçatiba), o descarte inadequado e precário de resíduos sólidos, representam um risco crescente para os diversos ecossistemas costeiros e comprometem a biodiversidade e a geodiversidade deste magnífico ambiente. Essa situação é preocupante e reforça a necessidade de realização de estudos voltados para o monitoramento permanente de médio e longo prazo das atividades desenvolvidas na Ilha Grande. 


\section{Agradecimentos}

Ao Instituto Estadual do Ambiente (INEA) pela autorização de pesquisa (Número 017/2014); ao Centro de Estudos Ambientais e Desenvolvimento Sustentável (CEADS) da UERJ, pela logística de campo; ao Laboratório de Sedimentologia da UFF e Laboratório de Dinâmicas da Natureza da FFP-UERJ pelas análises laboratoriais.

\section{REFERÊNCIAS BIBLIOGRÁFICAS}

BAPTISTA, E. C. S. Sensibilidade ambiental do LITORAL DA ILHA Grande (ANGRA dOS REIS, RJ) A EVENTOS DE DERRAMAMENTO DE Óleo. $112 \mathrm{~F}$. Dissertação (Mestrado em Geografia) UNIVERSIDADE DO ESTADO DO RIO DE JANEIRO, FACUldade DE FormaçÃo DE PROFESSORES. P. 114, 2017.

$$
\text { DISPONÍVEL }
$$

HTTPS://SUCUPIRA.CAPES.GOV.BR/SUCUPIRA/PUBLIC/CONS ULTAS/COLETA/TRABALHOCONCLUSAO/VIEWTRABALHOCON CLUSAO.JSF?POPUP $=$ TRUE $\&$ ID $\quad$ TRABALHO $=5552239 \#$

BELO, W. C.; DIAS, G. T. M.; DIAS, M. S. O FUNDO MARINHO DA BAÍA DA ILHA GRANDE, RJ: O RELEVO SUBMARINO E A SEDIMENTAÇÃO NO CANAL CENTRAL. Revista Brasileira de Geofísica, V. 20 (1) P. 515, 2002. HTTP://DX.DOI.ORG/10.1590/S0102$\underline{261 \times 2002000100001}$

BIRD, E. C. F. Coastal Geomorphology: An INTRODUCTION. JOHN WILEY \& SONS LTD. ENGLAND, P. $411,2008$.

BULHÕES, E. ; FERNANDEZ, G. B.; OLIVEIRA FILHO, S. R.; PEREIRA, T. G. COASTAL IMPACTS INDUCED BY Storm WaVes betWeen CAPE Frio and CAPE Buzios, RiO dE JANEIRO, BRAZIL. Journal of CoAstal RESEARCH, SPECIAL ISSUE 75, P. 1047-1051, 2016. HTTPS://DOI.ORG/10.2112/SI75-210.1

CARTER, R. W. G. CoAstal Environments: An Introduction to the Physical, Ecological and Cultural Systems of Coastlines. LONDON, ACADEMIC PRESS. P. 99-134, 1988.

DAVIS JUNIOR, A. R. CoAstal SEdimentary ENVIRONMENTS. SPRINGER-VERLAG, NEW YORK, P.716, 1985.

DAVIS JUNIOR, A. R.; FITZGERALD, D. M. BEACHES AND CoAsts. BLACKWELL PUBLISHING P.115-166, 2004.
DHN, FolHa de Bordo, FB-1500-001/79. Diretoria de hidrografia e Navegação da Marinha do BRASIL, 1980.

ECCARD, L. R.; SILVA, A. L. C.; SILVESTRE, C. P. VARIAÇÕES MORFOLÓGICAS NAS PRAIAS OCEÂNICAS DE Niterói (RJ, BRASIL) EM RESPOSTA A INCIDÊNCIA DE ondas de tempestades. Revista Brasileira de GeOgRAfia FísicA, V.10, N.01, P. 206-218, 2017. HTTP://DX.DOI.ORG/10.5935/1984-2295.20170011

FOlK, R. L. Petrology of sedimentary rocks. Hemphill Publishing Company. Austin, EuA. P. 182, 1980.

friedman, G. M.; SANDers, J. E. Principles of SEdimentology. JOHN Wiley \& SONS. NeW YORK, P. 792, 1978.

GODOI, V. A.; CALADO, L.; WATANABE, B. W.; YAGINUMA, L.; PEREIRA, M. B. EVENTO EXTREMO DE ONDAS NA BAÍA DA ILHA GRANDE: UM ESTUDO DE CASO. Boletim do Observatório ambiental alberto Ribeiro Lamego, V. 5, P. 28-44, 2011. HTTPS://DOI.ORG/10.5935/2177-4560.20110014

gralato, J. C. S. DinÂmica de praia e VULNERABILIDADE Às ONDAS DE TEMPESTADES DO LITORAL ORIENTAL DA ILHA GRANDE (ANGRA dos Reis - RJ). Dissertação (Mestrado em Geografia) Programa de Pós-Graduação em Geografia, FACULDADE DE FORMAÇÃO DE PROFESSORES - UERJ, SÃO Gonçalo, Rio de JANEIRo. P. 135, 2016. Disponível EM:

HTTPS://SUCUPIRA.CAPES.GOV.BR/SUCUPIRA/PUBLIC/CONS ULTAS/COLETA/TRABALHOCONCLUSAO/VIEWTRABALHOCON CLUSAO.JSF?POPUP $=$ TRUE\&ID TRABALHO $=4458304 \mathrm{\#}$ 
inea, instituto estadual do Ambiente. Plano de manejo do Parque Estadual da Ilha Grande. Rio DE JANEIRO. P. 558, 2011. DisPonível EM: HTTP://WWW.INEA.RJ.GOV.BR/PORTAL/AGENDAS/BIODIV ERSIDADEEAREASPROTEGIDAS/UNIDADESDECONSER VACAO/INEA012819

inea, instituto estadual do Ambiente. Parque Estadual da ILHA GRANDE: PLANO de MANEJo (FASE 2) / Resumo executivo. Rio de Janeiro. P. 98, 2013. DISPNÍVEL EM: HTTP://WWW.INEA.RJ.GOV.BR/PORTAL/AGENDAS/BIODIV ERSIDADEEAREASPROTEGIDAS/UNIDADESDECONSER VACAO/INEA0020167

Komar, P. D. Beach Processes and Sedimentation. Prentice-Hall, New Jersey. P. 429, 1976

Laing, A. K. An Introduction to Ocean Waves. in: Secretariat of the World Meteorological Organization. Guide to WaVe Analysis and Forecasting. World Meteorological Organization. GENEVA - SWITZERLAND, SECOND EDITION, WMO - No 702. P. 1-14, 1998.

LINS-DE-BARROS, F. M.; MUEHE, D. C. E. H. AVALIAÇÃO LOCAL DA VULNERABILIDADE E RISCOS DE INUNDAÇÃO NA ZONA COSTEIRA DA REGIÃO DOS LAGOS, Rio DE JANEIRO. QuATERnARY AND ENVIRONMENTAL Geosciences, V. 2 (1), P. 55-66, 2010. HTTP://DX.DOI.ORG/10.5380/ABEQUA.V2I1-2.14106

MACIEL N.C., ARAUJO D.S.D., MAGNANINI A. Reserva Biológica estadual da praia do Sul (ILHA Grande, ANGRA dos REIS, RJ): CONTRIBUIÇÃo PARA CONHECIMENTO DA FAUNA E FLORA. BOL. FBCN, 19: P. 126-148, 1984.

MAHIQUES, M. M. ConsIderações SOBRE os SEDIMENTOS DE SUPERFÍCIE DE FUNDO DA BAÍA DA ilha Grande, Estado do Rio de Janeiro. DissertaÇÃo (MESTRADO) - INSTITUTO OCEANOGRÁFICO, Universidade de São Paulo, São Paulo. P. 139, 1987. DISPONÍVEL EM: HTTPS://TESES.USP.BR/TESES/DISPONIVEIS/21/21132/T DE-13102009-164145/PUBLICO/MAHIQUES.PDF
MAHIQUES, M. M.; FURTADO, V. V. UTILIZAÇÃO DA ANÁLISE DOS COMPONENTES PRINCIPAIS NA CARACTERIZAÇÃO DOS SEDIMENTOS DE SUPERFÍCIE DE Fundo dA BaÍA dA ILHA Grande (RJ). Boletim do INSTITUTO OCEANOGRÁFICO DA UNIVERSIDADE DE São Paulo, São Paulo, V.37(1). P. 1-19, 1989. HTTP://DX.DOI.ORG/10.1590/S0373$\underline{55241989000100001}$

MEDEIROS, M. F. DE. Estudo DA SEQUÊNCIA SEDIMENTAR HOLOCÊNICA DAS bAÍAS DA RIBEIRA E Parati (Baía da ilha Grande-RJ) através de MÉTOdos SÍSMICOS E ANÁLISES DE TESTEMUNHOS. Dissertação (Mestrado). Programa de PósGraduação em Geologia E Geofísica Marinha, UFF. NiteRóI, RJ. P. 120, 2006.

MESQUITA C.A.B. RPPN dA MATA ATLÂNTICA: UM OLHAR SOBRE AS RESERVAS PARTICULARES DOS Corredores de Biodiversidade Central e da Serra do Mar. Aliança para Conservação da Mata Atlântica. SÃo PaUlo, 2004. Disponível em HTTPS://ISSUU.COM/REDERPPN/DOCS/UM-OLHAR-PARAAS-RPPNS-DOS-CORREDORES-DA-MATA-ATLA

MMA/SBF/GBA, Ministério do Meio Ambiente / SECRETARIA de BiodiverSidAde E FLoRESTAS / GerênCiA de Biodiversidade Aquática e Recursos Pesqueiros.

PANORAMA da CONSERVAÇÃo dos ecossistemas COSTEIROS E MARINHOS NO BRASIL - BRASÍLIA: 148 P, 2010. DISPONÍVEL EM: HTTPS://WWW.MMA.GOV.BR/ESTRUTURAS/205/ PUBLICAC AO/205 PUBLICACAO03022011100749.PDF

MOHRIAK, W. U. Bacias Sedimentares da Margem CONTINENTAL BRASILEIRA. IN: BIZZI, L. A.; SCHOBBENHAUS, C.; VIDOTTI, R. M.; GONÇALVES, J. H. (Editores). Geologia, Tectônica e Recursos Minerais do Brasil. CPRM - SeRviço Geológico do BRASil. BRASÍlia, P. 87-94, 2003. DisPoníVEL EM: HTTP://RIGEO.CPRM.GOV.BR/XMLUI/BITSTREAM/HANDLE/D OC/5006/GEOLOGIA TECTONICA.PDF?SEQUENCE $=2$

MUEHE, D. C. E. H. Sedimentology and Topography of a High Energy Coastal Environment Between Rio de Janeiro and Cabo frio - Brazil. Anais da ACAdemia Brasileira de Ciências. 51 (3), PP. 473481, 1979. 
MUEHE, D.; LINS-DE-BARROS, F.M.; OLIVEIRA, J. F.; KLUMB-OLIVEIRA, L. PULSOS EROSIVOS E RESPOSTA MORFODINÂMICA ASSOCIADA A EVENTOS EXTREMOS NA costa leste do Estado do Rio de Janeiro. Revista Brasileira de GeOMORFologia, v. 16, P. 369-386, 2015. HTTP://DX.DOI.ORG/10.20502/RBG.V16I3.728

NORDSTROM, K. F. EROSION CONTROL STRATEGIES FOR bay and estuarine beaches. Coastal Management, VOL. 17, P. 25-35, 1989. HTTPS://DOI.ORG/10.1080/08920758909362072

OLIVEIRA R.R. AÇÃO ANTRÓPICA E RESULTANTES SOBRE A ESTRUTURA E COMPOSIÇÃO DA MATA ATLÂNTICA NA ILHA GRANDE, RJ. RODRIGUÉSIA, VOL. 53(82): P. 33-58, $2002 . \quad$ HTTP://DX.DOI.ORG/10.1590/2175$\underline{78602002538203}$

OLIVEIRA, B. R. G.; SILVA, T. M.; ROSSO, T. C. A. ESTILOS FLUVIAIS NAS BACIAS HIDROGRÁFICAS DA VILA Dois Rios, ilha Grande (RJ). Revista Geonorte, EDIÇÃO EsPECIAL 4, V.10, N.1, P. 281-285, 2014. HTTP://WWW.PERIODICOS.UFAM.EDU.BR/INDEX.PHP/REVIS TA-GEONORTE/ARTICLE/VIEW/1562/1450

PARDAL, M. T. DA C. Mudanças morfológicas e SUAS IMPLICAÇÕES PARA A ESTABILIDADE DA PRAIA NA Região do Recanto de ItaIPUaÇú, Maricá, RJ. Dissertação (Mestrado em Geologia e Geofísica MARINHA) - DePARTAMENTO DE GEOlogia, UniVersidAdE Federal Fluminense, Niterói, Rio de Janeiro. P. 148, 2009.

PetTiJohn, F. J. Sedimentary Rocks. Third Ed. HARPER AND ROW PUBLISHERS. P. 68-81, 1975.

PINHEIRO, A. B.; SILVA, A. L. C.; SILVESTRE, C. P.; BARBOSA, T. M.; CORRÊA, L. F.; PINTO, V. C. S. DINÂMICA E EROSÃO EM PRAIA DE BAIXA ENERGIA: Jabaquara, paraty (RJ). Anais do Simpósio Brasileiro de Geografia física e Aplicada, P. 1$12,2019$.

ROSA, M. S.; PINHEIRO, T. S. A. D.; FERNANDES, R. L.; SALGADO, C. M.; RIBEIRO, G. P. GeOgrafiA FísicA E GEOTECNOLOGIAS: APLICABILIDADE NO ESTUdO

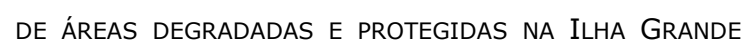
(ANGRa dos Reis, Rio de Janeiro - Brasil). ANais do encontro de Geografia da américa latina EGAL, Buenos Aires, ARgentina. P. 1-11, 2009.
SALGADO, C. M.; PEIXOTO, M. N. O.; MOURA, J. R. S. CARACTERIZAÇÃO ESPAÇO-TEMPORAL DA CHUVA COMO SUBSÍDIO À ANÁLISE DE EPISÓDIOS DE ENCHENTES NO MUNicíPIO de ANGRA dos ReIS, RJ. ReVISTA Geosul, V. 22, N. 44, P. 7-26, 2007. HTTPS://PERIODICOS.UFSC.BR/INDEX.PHP/GEOSUL/ARTICL E/VIEW/12607

SANTOS, C. L.; SILVA. M. A. M.; SALVADOR. M. V. S. DINÂMICA SAZONAL E OS EFEITOS DAS RESSACAS NAS praias de niterói/RJ. Revista Brasileira de GeociêncIAS, V. 34(3), P. 355-360, 2004. HTTP://PPEGEO.IGC.USP.BR/INDEX.PHP/RBG/ARTICLE/VIEW $\angle 9758 / 9119$

SILVA, A. L. C., SILVA, M. A. M., SANTOS, C. L. COMPORTAMENTO MORFOLÓGICO E SEDIMENTAR DA PRAIA DE ITAIPUAÇÚ (MARICÁ, RJ) NAS ÚLTIMAS TRÊS DÉCADAS. Revista Brasileira de Geociências, v.38(1), P. 87-97, 2008. HTTP://PPEGEO.IGC.USP.BR/INDEX.PHP/RBG/ARTICLE/VIEW $\angle 7569 / 6996$

SILVA, A. L. C.; SILVA. M. A. M.; SANTOS. C. L. MORFODINÂMICA E A ESTABILIDADE DA PRAIA DE Piratininga, Niterói (RJ). Revista Brasileira de GeociênCIAS, V. 39(4), P. 685-694, 2009. HTTP://PPEGEO.IGC.USP.BR/INDEX.PHP/RBG/ARTICLE/VIEW $\angle 7726 / 7153$

SILVA, A. L. C., SILVA, M. A. M., SOUZA, R. S., PINTO, M. L. V. THE ROLE OF BEACHROCKS ON THE EVOLUTION OF THE HOLOCENE BARRIER SYSTEMS IN RIO DE JANEIRo, SOUtheAstern BRAZIL. IN: GREen, A.N. AND COOPER, J.A.G. (EDS.), PROCEedings $13^{\text {TH }}$ INTERNATIONAL COASTAL SYMPOSIUM (DURBAN, SOUTH Africa), Journal of Coastal Research, Special ISSUE N. 70, P. 170-175, 2014A. HTTPS://WWW.JCRONLINE.ORG/DOI/PDF/10.2112/SI70$\underline{029.1}$

SILVA, A. L. C.; SILVA, M. A. M.; GRALATO, J. C. A.; SILVESTRE C. P. CARACTERIZAÇÃo GEOMORFOLÓGICA E SEDiMENTAR DA PLANÍCIE COSTEIRA dE MARICÁ (RIO DE Janeiro). Revista Brasileira de Geomorfologia, V. $15, \quad$ N. 2, P. 231-249, 2014B. HTTP://WWW.LSIE.UNB.BR/RBG/INDEX.PHP/RBG/ARTICLE/ VIEW/470/382 
SILVA, M. A. M., RESENDE, M. C. C. M. \& SANTOS, C. L. UM Estudo SOBRe a DinÂMicA das praias de Niterói (Baía de Guanabara, RJ). ANaIs dA Academia Brasileira de CiÊnCIAS, 71 (4) PP. 962967, 1999.

SILVA, M. A. M.; SILVA, A. L. C.; SANTOS, C. L.; SILVESTRE, C. P.; ANTONIO, R. V. M.; CUNHA, A. B. C.; GRALATO, J. C. A.; SOUZA, R. D. 2016. Praias DA Baía de Guanabara No ESTAdo do Rio de Janeiro.

Revista Brasileira de Geomorfologia, SÃo PAULO, V.17, N.2, P. 205-225, 2016. HTTP://WWW.LSIE.UNB.BR/RBG/INDEX.PHP/RBG/ARTICLE/ $\underline{\mathrm{VIEW} / 839 / 536}$

SILVA, M. A. M.; RESENDE, M. C. C. M; SANTOS, C. L. UM ESTUDO SOBRE A DINÂMICA DE PRAIAS DE NITERÓI (Baía de Guanabara, RJ). Anais da Academia Brasileira de CiÊnCIAS. No 71 (4), P. 966-967, 1999.

SOUZA, C. R. G. A eRosão COSTEIRA E OS DESAFios dA gestão costeira no Brasil. Revista da Gestão Costeira InTEgradA, V. 9(1), P. 17-37, 2009. HTTP://WWW.APRH.PT/RGCI/PDF/RGCI-147 SOUZA.PDF

SOUZA C. R. DE G.; LUNA, G. C. TAXAS DE RETROGRADAÇÃO E BALANÇO SEDIMENTAR EM PRAIAS SOB RISCO MUITO ALTO DE EROSÃO NO MUNICÍPIO DE UBATUBA (Litoral Norte de São Paulo). Quaternary and EnVironmental Geosciences, V. 1(1), P. 25-41, 2009.

HTTP://DX.DOI.ORG/10.5380/ABEQUA.V1I1.14489

tuCKer, M. E. Sedimentary Petrology: An

INTRODUCTION. $3^{\circ}$ V. HALSTED PRESS, BOSTON, P.252, 1981. 